\title{
Adaptive resilience of and through urban ecosystem services: a transdisciplinary approach to sustainability in Barcelona
}

\author{
Claudia De Luca $^{1}$, Johannes Langemeyer $^{2,3}$, Simeon Vaño ${ }^{4,5}$ Francesc Baró $^{2,6,7}$ and Erik Andersson $^{8,9}$
}

\begin{abstract}
Ecosystem services (ES) from urban green and blue infrastructure (GBI) provide cities and their citizens with benefits necessary to cope with present and future sustainability challenges. Long-term comprehensive urban greening strategies, policies, and plans are thus central to the development of sustainable, liveable, and resilient cities. However, urban greening strategies are increasingly tailored to provide short-term benefits, overlooking the dynamic character of cities, which face both changes in the capacity of GBI to provide benefits (e.g., in the face of climate change) as well dynamic needs and preferences for benefits over time as a result of changing demographic compositions. Starting with a literature review on GBI-relevant policies for the city of Barcelona, we: (1) investigated the presence of resilience thinking in the city's GBI-relevant policies through the application of the urban ecosystem services resilience assessment matrix; (2) investigated resilience thinking in the city's policies through the co-development of scenario narratives of possible futures and their implications for ES; and (3) applied the narratives through a participatory approach to enhance stakeholder thinking on adaptive policies based on possible shifts in ES provision and needs. Application of the matrix identified two main gaps to current GBI-relevant policies related to two main aspects of resilience: recognition and assessment of possible future disturbances and changes, and low understanding of social and structural diversity. Through the co-development of four future scenario narratives (aging and shrinking population, enhanced tourism, gender inequalities, and global warming), stakeholders identified the most susceptible ES in the city of Barcelona. Workshop participants indicated mental well-being, regulation of microclimate, social cohesion, air purification, physical recreation, runoff control, and soil permeability as ES with the widest capacity-demand mismatch. The results elicited discussion around GBI and ES resilience, addressing the need for intersectoral policy integration (including housing, education, and mobility) and for fostering a wider understanding of the role of institutions in providing for a resilient urban future. Through the use of scenario narratives, and highlighting the potential of co-creation, the proposed approach enhances critical thought around ES resilience among key players in the city. The study thereby supports the development of a comprehensive resilience strategy for Barcelona and indicates pathways for how other cities can change their current urban trajectory towards sustained ES flows.
\end{abstract}

Key Words: ecosystem services; green and blue infrastructure; participatory process; resilience principles; scenario narratives; urban greening policies

\section{INTRODUCTION}

With urbanization on the rise (Güneralp et al. 2017, UN 2019), ecosystem services (ES) provided by urban green and blue infrastructure (GBI) offer multiple health and well-being benefits necessary to cope with present and future urban challenges (Gómez-Baggethun and Barton 2013, Gascon et al. 2015, van den Berg et al. 2015). These ES include, for example, microclimate regulation, runoff control, and opportunities for outdoor recreation (Gómez-Baggethun and Barton 2013, Haase et al. 2014). Long-term urban policies and strategies can play a central role in maintaining and increasing ES to create more sustainable, liveable, and resilient cities (Ahern et al. 2014). However, current urban strategies often overlook the sectoral integration that is needed to harness the potential of GBI to support sustainable urban transformation and create resilience around human wellbeing (McPhearson et al. 2016). Moreover, to maintain well-being related benefits over time, cities need to build capacity to adapt both to external drivers of change, such as global climate change and pandemics, as well as to inherent changes, such as shifting demographic composition (e.g., due to an aging population or migration) and related changing demands for ES benefits from GBI over time.
The need to build urban resilience has increasingly gained attention in the last decade in both science and practice (e.g., Meerow et al. 2004, Quinlan et al. 2016, Moser et al. 2019). Resilience studies help us to understand complex social-ecological systems and how to plan and manage them for sustainability, not least with respect to climate change (Elmqvist et al. 2019). However, urban resilience is generally vaguely defined, which makes its application difficult as an analytical framework (Sellberg et al. 2018). Resilience is often interpreted as being positive, which is misleading. In response, Elmqvist et al. (2019) introduced a more precise understanding of urban resilience connected to sustainable transformations of urban areas. Whereas urban sustainability and ES are considered a normative concept representing a "positive" vision for the future of the society (Schröter et al. 2014, Romero-Lankao et al. 2016), the authors describe resilience as a neutral, non-normative concept (e.g., Ernstson 2013) and an intrinsic property of social-ecological urban systems. To fit with a system in constant change, resilience is defined as the "capacity of an urban system to absorb disturbances, reorganize and maintain essentially the same functions over time and continue to develop along a particular trajectory"(Elmqvist et al. 2019:269). This interpretation suggests

\footnotetext{
${ }^{1}$ Department of Architecture, Alma Mater Studiorum - Università di Bologna, ${ }^{2}$ Institute of Environmental Science and Technology (ICTA), Universitat Autònoma de Barcelona, Barcelona, Spain, ${ }^{3}$ Humboldt Universität zu Berlin, Institute of Geography, Berlin, Germany, ${ }^{4}$ Department of Ecology and Environmental Sciences, Constantine the Philosopher University in Nitra, Nitra, Slovakia, ${ }^{5}$ Global Change Research Institute of the Czech Academy of Sciences, Brno, Czech Republic, ${ }^{6}$ Department of Geography, Vrije Universiteit Brussel (VUB), Brussels, Belgium, ${ }^{7}$ Department of Sociology, Vrije Universiteit Brussel (VUB), Brussels, Belgium, ${ }^{8}$ Stockholm Resilience Centre, Stockholm University, Stockholm, Sweden, ${ }^{9}$ NorthWest University, Unit for Environmental Sciences and Management, Potchefstroom, South Africa
} 
that resilience can be a barrier to the desired transformations if the city is following a pathway that is not sustainable, and that it needs to be reduced to enable transformation (Moore et al. 2018) toward sustainability. In framing these considerations, we position the GBI potential of generating multiple ES as the core feature to be sustained. We argue that this more dynamic definition will help to secure human well-being in the face of challenges related to climate change and social transformations.

Securing a resilient ES flow in cities has raised substantial policy interest (Gómez-Baggethun and Barton 2013, McPhearson et al. 2015, Elmqvist et al. 2017, 2019, Simon et al. 2018). Nevertheless, tailored policies and interventions are needed to reduce the resilience of barriers to equitable access to ES (Langemeyer and Connolly 2020). Moreover, tailored policies should build and increase resilience around the factors that enable the flow of ES benefits over time (McPhearson et al. 2015). In light of diverse and changing demands for ES in the future (Langemeyer and Connolly 2020), planners and decision makers must address uncertainties when designing adaptive policies. As Walker et al. (2001) suggest, policies should be "devised not to be optimal for a best estimate future, but robust across a range of plausible futures." However, from a practical perspective, it is far from obvious what these barriers and enabling factors are, and how to engage with their resilience.

Transforming or guiding cities toward desired and sustainable futures, in which ES capacity aligns with ES demands (Villamagna, et al. 2013, Baró et al. 2016) requires improved integration of resilience thinking into urban policies. Here, we address three specific questions for guiding ES resilience-oriented policy-making: "resilience of what?", "resilience to what?", and "resilience for whom?" This strategy implies a broader understanding of: (1) external (e.g., climate change) and inherent drivers of change (e.g., demographic changes; i.e., "resilience to what?"); (2) whether and how these drivers and changes affect the generation of urban ES and the realization of their benefits (i.e., "resilience of what?"); and (3) who has access to ES considering evolving ES demands over time (i.e., "resilience for whom?").

\section{CONCEPTUAL APPROACH}

To govern the flow of ES benefits effectively, urban policies must acknowledge urban ES benefits as fundamentally co-produced by natural and human assets (Ernstson 2013, Langemeyer and Connolly 2020). We understand GBI as the source of local ES, which are negotiated, regulated, and distributed across urban social-ecological systems (Andersson et al. 2019). The wider social-ecological system is, in turn, strongly influential in shaping and maintaining the quality and functionality of GBI. To gain a systemic understanding of GBI and the availability, accessibility, and fair distribution of ES, Andersson et al. (2019) proposed a framework of three interconnected systemic filters: infrastructure, institutions, and perceptions. These filters are recognized factors that affect the capacity of GBI to produce ES and hinder or facilitate the realization of ES benefits by different beneficiaries. Although GBI is critical to guarantee the capacity of ES, ES are realized in the complex interplay of grey infrastructure (different types of housing developments, transportation networks, etc.), actors, roles, rights, responsibility, and management (institutions), as well as specific needs, knowledge, practice, and identities (perceptions; Andersson et al. 2019).
We combined Andersson et al.'s (2019) three interconnected filters approach (infrastructure, institutions, and perceptions) with seven ES resilience principles proposed by Biggs et al. (2012): (1) maintain diversity and redundancy, (2) manage connectivity, (3) manage slow variables and feedbacks, (4) foster an understanding of complex adaptive systems, (5) encourage learning and experimentation, (6) broaden participation, and (7) promote polycentric governance systems. We argue that adapting the ES resilience principles to the urban realm could support policymaking in pursuing resilience around the flow of ES by anticipating and systemically adapting urban social-ecological systems to different drivers of change (see the urban ecosystem services resilience assessment matrix in Appendix 1). The (assumed) objective of urban policies would be to sustain and maintain both currently used and potential but latent GBI benefits over time. We believe that by applying and adapting Biggs et al.'s (2012) seven principles to the three filters in an urban context, policies (as an institutional tool) can shape infrastructures to ensure their maintenance and connections (principles 1 and 2). Also, translating into practice principles 3 and 4 , through constant monitoring of slow variables and feedback interactions among all three filters, would support policy adjustments and adaptations to multiple drivers of change. Although policies can reframe the beneficiaries' perceptions and strengthen their capacity to benefit from the system, guiding the system through changes (principle 5), beneficiaries' perceptions can also influence infrastructure through GBI co-design and as well bottom-up influences on GBI governance (principles 6 and 7; Barnaud et al. 2018). Departing from the premises of this conceptual framework (Fig. 1), we address four research objectives, as described below, to trigger policy adaptations that enable a resilient ES flow.

Integrating ES resilience principles into policies and planning approaches (institutions) can function as a lens for identifying leverage points for unlocking the flow of ES from nature to humans, under both current and potential future conditions (Biernacka and Kronenberg 2018, Elmqvist et al. 2019). Thus, the first objective of our empirical approach is to address ES resilience within GBI policies and question whether policies can ensure the generation of urban ES and the subsequent realization of their benefits over time ("resilience of what?").

To avoid narrowly focusing on single external drivers of change (e.g., climate change) in policy development and definition, our second research objective was to co-develop scenario narratives to trigger multilayered resilience thinking (Schewenius et al. 2014, Wiese 2016). This objective is meant to support the integration of different drivers of change into policy-making, including their interactions, feedbacks, and combined effects on the capacity and demand of ES ("resilience to what?").

Based on the assumption that GBI benefits tend to be distributed unequally among different social groups (e.g., Ernstson 2013, Baró et al. 2019), we assume that building resilience around a trajectory of sustainable development needs to be inclusive (Tozer et al. 2020). Therefore, we need to understand not only which ES would be more susceptible to changes under different future scenarios, but also which social groups might become excluded from the future ES flow of benefits. The third objective is to develop a participatory approach to understand the potential 
Fig. 1. The filters (perceptions, institutions, infrastructures) and ecosystem services (ES) resilience principles (P1 to P7) that affect the capacity of urban green and blue infrastructure (GBI) to produce ES and unlock the flow of benefits, under different drivers of changes. The study framework is built on Biggs et al. (2012) and Andersson et al. (2019), using the ES resilience principles and filters as pathways for sustainable policy-making. Arrows from left to right suggest that policy-making might work through the systemic filters and resilience principles to ensure resilient ES flow and counteract drivers of change that undermine the uptake of GBI benefits.

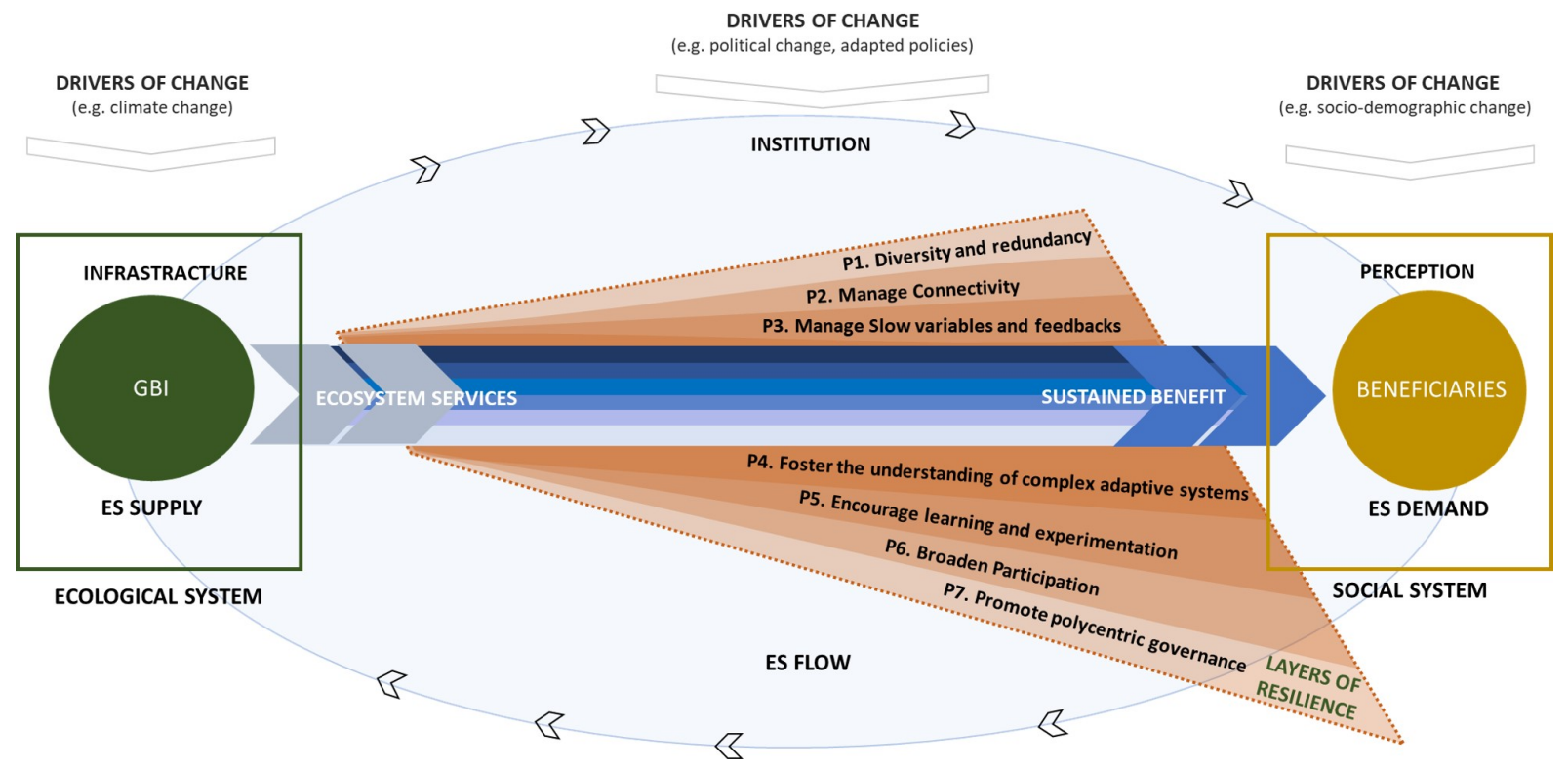

changes in ES capacity (infrastructure), citizens' desires or needs (perceptions), and the future distribution of benefits among different social groups ("resilience for whom?").

Our fourth objective is to analyze the proposed policy measures and their integration of resilience thinking into such policies. Navigating the complexity of assessing future scenarios into participatory resilience thinking will lead to the identification of adaptive policy measures for building resilience around the future flow of urban ES, taking into consideration their capacity and demand. This objective will allow us to assess the proposed conceptual and participatory framework for fostering resilience thinking around ES in urban systems.

\section{CASE STUDY}

Our empirical study focused on the city of Barcelona. With 1.62 million inhabitants, Barcelona is the second largest city in Spain and one of the most densely populated cities in Europe, with approximately 16,000 people $/ \mathrm{km}^{2}$ (Barcelona City Council Statistical Yearbook 2019). In recent years, the Barcelona city council has embraced an ES-based approach to urban greening policy, developing several strategies and plans to support the city's trajectory toward a more sustainable future (these plans include the Barcelona Green Infrastructure and Biodiversity Plan 2020 [Ajuntament de Barcelona 2014], Trees for Life: Master Plan for Barcelona's Trees 2017-2037 [Ajuntament de Barcelona 2017], and the Climate Action Plan, Pla Clima 2018-2030 [Ajuntament de Barcelona 2018a]). The Climate Action Plan identifies greening and the related provision of urban ES as one of the most important measures for taking climate action. At the time of writing, Barcelona city council was working on the development of an urban resilience strategy (Ajuntament de Barcelona 2018b) through the coordinated work of several city departments including the city's Urban Resilience Department. Our study is embedded in the current discourse around resilience building and is intended to assess urban ES resilience and explore new policy options to secure and unlock the future flow of ES. It builds upon a workshop that was part of an ongoing stakeholder engagement process organized by the Institute of Environmental Science and Technology (ICTA) in Barcelona since 2013 (in the context of the European research projects FP7-Openness, BiodivERsA3ENABLE, EC-H2020-NATURVATION). The stakeholder engagement process was initiated to promote new relations, knowledge sharing, and empowerment among GBI-related stakeholders in Barcelona. The process creates an interface of current urban policies with research, as well as civic and private initiatives, touching upon themes such as public health, social inclusivity, and just planning in urban greening.

\section{METHODS}

We adopted a transdisciplinary and mixed-method research approach (Turnhout 2019) of sequential steps inspired by participatory multi-criteria evaluation approaches (e.g., Langemeyer et al. 2018) to address urban ES resilience. First, we developed an urban ecosystem services resilience assessment matrix to perform a systematic analysis of how municipal sustainability policies aligned with adapted ES resilience principles (following Biggs et al. 2012, Borgström et al. 2015, Nykvist et al. 2017, Andersson et al. 2019). Second, we co-created four scenario narratives to investigate potential external drivers of or inherent changes in the social-ecological system (Nelson et 
Table 1. Urban ecosystem services resilience assessment matrix (based on Biggs et al. 2012, Borgström et al. 2015, and Nykvist et al. 2017).

\begin{tabular}{|c|c|c|}
\hline $\begin{array}{l}\text { Ecosystem } \\
\text { services }(\mathrm{ES}) \\
\text { resilience } \\
\text { principles }\end{array}$ & $\begin{array}{l}\text { Aspects } \\
\text { addressed }\end{array}$ & $\begin{array}{l}\text { Guiding questions } \\
\text { for the assessment }\end{array}$ \\
\hline P1, P4 & Diversity consideration & $\begin{array}{l}\text { Biological diversity: } \\
\text { How are genetic, species, and landscape-level diversity addressed? } \\
\text { How are interactions between species and ecological succession addressed? } \\
\text { How is complementarity in the landscape addressed? } \\
\text { Social diversity: } \\
\text { How are the different socio-economic components of the urban areas analyzed? } \\
\text { How are cultural and historical values considered? } \\
\text { Structural diversity: } \\
\text { How is urban structure (in terms of differences and components of neighborhoods) considered? } \\
\text { Is spatial and temporal scale considered? }\end{array}$ \\
\hline P1, P5, P6 & $\begin{array}{l}\text { Use of different knowledge } \\
\text { spheres }\end{array}$ & $\begin{array}{l}\text { What kind of knowledge is used? } \\
\text { How is involvement of different stakeholders in planning, design, management, and monitoring addressed? } \\
\text { Is spatial and temporal scale considered? }\end{array}$ \\
\hline $\mathrm{P} 2$ & Physical connectivity & $\begin{array}{l}\text { How is green and blue infrastructure (GBI) addressed (structures, nodes, networks, species migration)? } \\
\text { How is mobility and physical accessibility addressed? } \\
\text { How is information flow addressed? } \\
\text { Are spatial and temporal scale considered? }\end{array}$ \\
\hline P3, P4 & Disturbance regimes & $\begin{array}{l}\text { What disturbances are recognized? } \\
\text { What responses are addressed (coping, adapting, transforming)? }\end{array}$ \\
\hline P3, P4 & $\begin{array}{l}\text { Assessment of forecast, } \\
\text { possible changes, and } \\
\text { uncertainty }\end{array}$ & $\begin{array}{l}\text { What changes are recognized, e.g., climate, demographical, economic, political, technological innovation, } \\
\text { human preferences and lifestyle (cultural ES), tourism, housing, land-use planning? } \\
\text { Are changes in relation to future supply and demand of ES considered and addressed? } \\
\text { How are monitoring, evaluation, and revision addressed? } \\
\text { Are spatial and temporal scale considered? }\end{array}$ \\
\hline P3, P4, P5 & System knowledge approach & $\begin{array}{l}\text { How are the management steps of monitoring, evaluating, revising, and adapting addressed? } \\
\text { How are emergent signals captured? } \\
\text { How are responses to changes addressed? }\end{array}$ \\
\hline $\mathrm{P} 3, \mathrm{P} 4, \mathrm{P} 5$ & Institutional flexibility & $\begin{array}{l}\text { In what ways are the approaches to GBI reactive or proactive? } \\
\text { How are alternative approaches recognized? } \\
\text { What kind of formulations are used, e.g. shall, should, recommend? }\end{array}$ \\
\hline $\begin{array}{l}\text { P1, P2, P6, } \\
\text { P7 }\end{array}$ & Polycentric governance & $\begin{array}{l}\text { How is governance organized (centralized/decentralized, single/multiple actors, sector divided, strong/weak } \\
\text { linkages across levels, sectors and actors)? } \\
\text { How is collaboration between actors addressed? } \\
\text { How is responsibility organized? }\end{array}$ \\
\hline
\end{tabular}

al. 2005). The themes for the scenarios were defined through multiple iterations with the city's Urban Resilience Department. Third, the narratives were used in an expert stakeholder workshop to trigger critical thinking about possible future shifts in capacity and demand of ES. Finally, this new understanding was used to prompt expert stakeholders to reflect on the adaptation required for a transition to more desirable futures and to propose targeted policy interventions.

\section{Policy analysis}

We limited the analysis to policies developed at the city level and those that were relevant to the urban GBI and related ES development that dealt with sustainability, climate, and greening. Ten GBI-related policies were screened according to their potential alignment with and treatment of urban ES and their relevant resilience aspects (Appendix 2). The process followed a two-step approach. The first step included the screening of all 10 policies, with two objectives: (1) to translate the ES resilience principles into a context-relevant articulation that could inform an understanding of "resilience of what and to what?", and (2) to verify and assess the relevance and scope of the selected policies relative to the ES resilience framework. Consistent with Geneletti and Zardo (2016) and Rozas-Vásquez et al. (2018), our policy screening did not employ a strict keyword-based content analysis, but relied on both explicit and non-explicit qualitative content analysis applied to all sustainability-related city policies. Neither ES nor the resilience terminologies are yet standardized, and both are contingent on the context and must be sensitive to alternative languages (e.g., Camps-Calvet et al. 2016, Meerow et al. 2016, Sellberg et al. 2018). Thus, in the first screening step, we translated the generic ES resilience principles identified by Biggs et al. (2012) to a case-relevant set of variables described in a language that resonated with how the policies were formulated.

We then performed a full analysis based on the urban ecosystem services resilience assessment matrix (Table 1). This matrix builds on Biggs et al. (2012), Borgström et al. (2015), Nykvist et al. (2017), and Andersson et al. (2019), and aims at adapting the ES resilience principles to the urban realm. Assessment variables relating to the ES resilience principles spanned sociocultural and biological diversity, urban morphology, planning approaches and normative context, consideration of external drivers (tourism, climate change, housing, technological innovation, demographic and political change), and inherent changes (human preferences and lifestyle) in the urban social-ecological system (Table 1). We translated qualitative judgments (high, medium, and low) 
regarding the level of incorporation of the ES resilience principles into each policy using a score from 1 (low incorporation) to 5 (high incorporation) to facilitate the representation of the results. The connections between the variables and the seven ES resilience principles are detailed in Appendix 1.

\section{Co-development of scenario narratives}

The development of scenario narratives as input to the expert stakeholder workshop was done in close collaboration with the city's Urban Resilience Department in spring 2019. Scenario narratives describe plausible futures affecting Barcelona's socialecological systems configuration (Palomo et al. 2011, Priess and Hauck 2014). The co-development of scenario narratives served, in particular, to identify and highlight critical external drivers of change and inherent system changes with potential negative effects on resilient ES flow, such as mismatches of ES capacity and demand (Villamagna et al. 2013, Baró et al. 2016). The following nine ES were deemed relevant for purposes of this study: regulation of microclimate, runoff control, air purification, carbon sequestration, noise reduction, social cohesion, physical recreation, mental well-being, and tourism recreation. This selection of ES, which was adapted through discussions with the Urban Resilience Department, built on results from a preceding workshop with local stakeholders that focused on the prioritization of urban land uses for the local production of ES (Langemeyer et al. 2020).

\section{Participatory workshop}

The participatory workshop underlying this study took place in Barcelona on 6 June 2019 and involved 49 "expert stakeholders" (including the organizers) from 27 different organizations, including local nongovernmental organizations, private consultancies, small enterprises, different levels and departments of public administrations, and academia (Appendix 3). Following a general introduction of the results of the policy analysis, participants were divided into four heterogeneous breakout groups to work on two main exercises: simulation of shifting ES capacity and demand, and development of policy options to build resilience around ES. Each of the four groups was assigned to work with one specific scenario narrative, which situated the discussion on shifting ES capacity and demand. For each future scenario, participants were asked to assess potential changes in ES. Changes were assessed based on either: higher or lower number of users and relative awareness of benefits leading to increased or decreased pressure on urban GBI (indicating a shift in ES demand), or higher or lower availability of urban GBI leading to increased or decreased ES capacity. In the analysis of the workshop outcomes, numerical values were assigned to determine whether the assessed demand for and capacity of the single ES in a given scenario would: decrease substantially $(-2)$, decrease moderately $(-1)$, stay unchanged $(0)$, increase moderately $(+1)$ or increase substantially $(+2)$. In presenting the results, we use average values, but we acknowledge that considering the variability in responses may allow detection of a lack of consensus over changes in capacity and demand of ES and may be useful as an indicator of uncertainty (Langemeyer et al. 2018).

Based on the results of the ES capacity and demand assessment in the different scenarios, participants were asked to propose tailored and adapted policy interventions to build resilience around ES flows, tackling the specific issues arising from the different scenarios. The policies and interventions proposed were then clustered into different policy sectors together with the workshop participants, and proposed policy measures were further analyzed by the authors after the workshop. For each policy option proposed, the analysis identified which of the three systemic filters (infrastructure, institutions, and perceptions; Andersson et al. 2019) was primarily addressed, as well as which type of ES resilience principles were incorporated using the urban ecosystem services resilience assessment matrix (Table 1). This process allowed us to assess whether the applied resilience thinking approach was reflected in the policy measures proposed. Specific modalities of each workshop session are detailed in Appendix 4 and Appendix 5.

\section{RESULTS}

\section{Ecosystem services resilience in existing policies}

Based on the initial screening for the relevance of policies with regard to ES and resilience, six policies were considered highly relevant to ES resilience thinking. Nevertheless, two planning documents, the new Metropolitan Master Plan and the Superblock Programme, were not assessed using the developed matrix. The new master plan was still under development and not available at the time of the analysis. The Superblock Programme contains a series of diagnoses and guidelines for redesigning Barcelona neighborhoods and streets, developing action-oriented guidelines that were not considered relevant for the study. Four policies were analyzed in depth based on the urban ecosystem services resilience assessment matrix: the Barcelona Green Infrastructure and Biodiversity Plan 2020; the stimulus program for the city's urban green infrastructure; the Trees for Life: Master Plan for Barcelona's Trees 2017-2037; and the Climate Action Plan 2030. The policy screening revealed a general recognition of GBI as a source of ES provision and as an important asset for Barcelona's resilience strategy, particularly reflected in the city's greening and climate policies. In line with previous studies (Cortinovis and Geneletti 2018, de Luca et al. 2021), these urban policies primarily refer to regulating and cultural ES. To some extent, the policies also incorporated the ES resilience principles, which we assume will help to sustain ES in the future. Our analysis considered the degree of integration and consideration of the seven principles of ES resilience within four core policies (Fig. 2). We found the infrastructure filter, or the structural role of GBI in the city, was broadly addressed in terms of both the current state of GBI and future actions to improve the flow of ES (principles 1 and 2). For instance, the Climate Action Plan 2030 sets the goal to increase urban green space by $1.6 \mathrm{~km}^{2}$ (equivalent to an additional $1 \mathrm{~m}^{2} /$ inhabitant), which corresponds to an increase of $15 \%$ of the city's urban green areas by 2030, an ambitious objective in a compact city such as Barcelona.

Biological diversity and redundancy (principles 1 and 4) are specifically accounted for in terms of biodiversity preservation in the Barcelona Green Infrastructure and Biodiversity Plan 2020, in the stimulus program for the city's urban green infrastructure, and in the Trees for Life Master Plan. However, structural and socioeconomic diversity of the urban area are not addressed, except for in the Climate Action Plan 2030, which considers some socioeconomic issues along with demographic variables (principles 1 and 4). These issues include inherent changes such 
Fig. 2. Results from the policy analysis using the urban ecosystem services resilience matrix. The integration of the ecosystem services (ES) resilience principles (P1 to P7) into each green infrastructure policy ranges from 1 (low incorporation) to 5 (high incorporation). SES = socialecological system; CAS $=$ complex adaptive system

\section{ES resilience principles integration into policies}

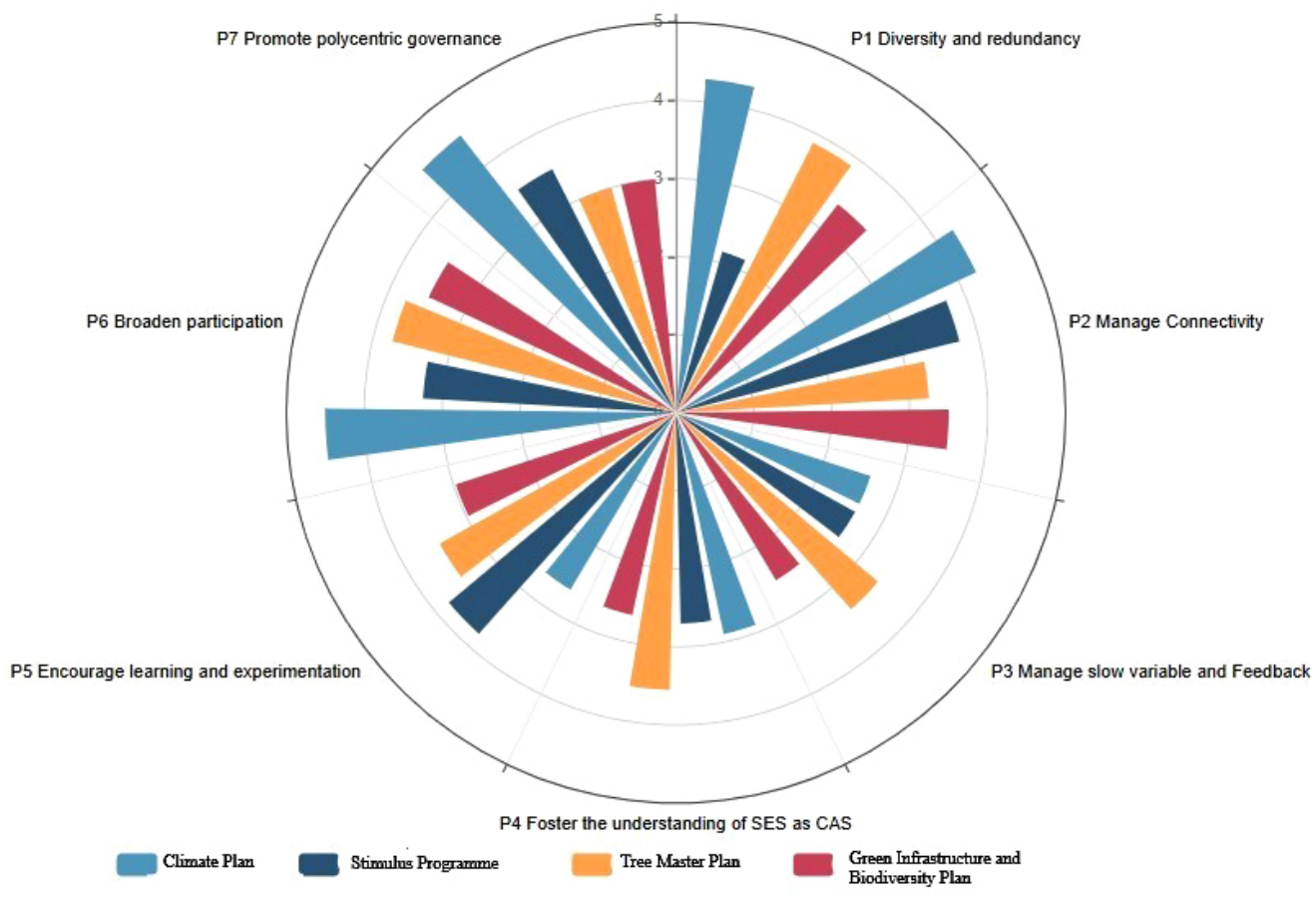

as possible increases in population, migration, and external drivers such as the effects of climate change on vulnerable neighborhoods and populations. The Climate Action Plan 2030 also refers to other relevant policies and plans, clearly showing links, connections, synergies, and opportunities with other policy sectors, acknowledging institutional flexibility and a systemic approach (principles 3, 4, and 5). None of the other three plans account for possible shifts in future ES demands, thus neglecting the perceptions filter, at least in the face of systemic changes (principles 3 and 4). Furthermore, the policy analysis indicated an explicit but one-dimensional focus on adaptation to climate change and general lack of attention to the management of other disturbances and drivers of change (e.g., climate, demographic, economic, political, technological innovation, human preferences and perceptions, tourism, housing, and land-use planning; principles 3 and 4). Greening strategies did recognize major disturbances caused by plagues and climate-related events, but did not consider other possible changes and disturbances (principles 3 and 4), such as those related to growing and shifting ES demands or capacities.

\section{Scenarios of change affecting ecosystem services resilience}

After several iterations with the Urban Resilience Department, four scenarios were proposed as the most relevant drivers of change to Barcelona's resilient ES flow: an aging and shrinking population, enhanced tourism, gender inequalities, and global warming (Table 2, Appendix 6). The four scenarios and the results of the policy analysis constituted the entry points for triggering participants' thoughts on possible disturbances and changes in capacity and demand sides of critical ES in the future during the stakeholder workshop. It is worth highlighting that the four scenarios were defined in spring 2019 before the global COVID-19 pandemic and the ensuing tourism crisis.

\section{Future ecosystem services capacity-demand gaps and potential policy responses}

Shifting ecosystem services capacity and demand

During the participatory workshop, stakeholders were asked to assess and discuss the changes in capacity and demand for each ES to explore the potential gap between the growing demand for and recessing capacity of given ES (Fig. 3). Across the four breakout groups working on the different scenarios, participants generally assessed that the ES demand will remain stable or increase, whereas the capacity of ES will remain unchanged or decrease. The discussions centered around ES that were deemed critical for urban sustainability and citizen's well-being, including regulating ES such as microclimate regulation, air pollution, and runoff control (Larondelle et al. 2014), and cultural ES such as mental well-being, physical recreation, and social cohesion (Andersson et al. 2015). The workshop revealed that mental wellbeing is the ES most susceptible to future changes, indicated by the capacity-demand gap (Fig. 3), followed by microclimate regulation, social cohesion, air purification, physical recreation, and runoff control and soil permeability. In contrast, noise 
Table 2. Four scenario narratives co-developed with the Urban Resilience Department. Each scenario is centered around a single narrative that represents a major challenge for urban sustainability.

\begin{abstract}
Scenario \#1 Aging and shrinking population
There is an outmigration of the young population and ageing of the resident population. The pressures on health, mobility, housing, job availability, and social services have increased substantially. The resulting effects are depression and loneliness in elderly people, a lack of opportunities to engage (socially and economically), and in public health and well-being. The city lacks accessible open green spaces which have the capacity to provide manifold social and environmental benefits.
\end{abstract}

\section{Scenario \#3 Gender inequalities}

An increasing number of women are reporting negative experiences from their visits to open spaces, also due to misperception and disinformation. Public spaces are dominantly used by men due to changes in users' perceptions. Equal access to green and open public spaces is questioned. Women's access to green spaces is limited, as they perceive them to be unsafe. The female population is deprived of benefits related to urban nature.
Scenario \#2 Enhanced tourism

Mass tourism is a source of wealth but also of complex challenges. The pressures on housing, services, and urban space availability as well as on the urban environment have substantially increased. The effects include rising prices, increase in illegal activities, overcrowded and degraded open spaces, and changing attitudes of residents living in affected central neighborhoods. Affected residents are deprived of available green spaces and beaches for recreation. Several local movements have emerged and taken action.

Scenario \#4 Global warming

Climate change has intensified and is affecting the city and its residents. Increase in the number of torrid days, droughts, fires, rain-shortages, and water scarcity presents an immense challenge for the future of the city. Some residents are affected more than others, particularly vulnerable groups such as the elderly, children, and pregnant woman. Similarly, heavily built up areas are affected the most. An increased importance of friendly and climate-resilient open spaces is highlighted. reduction, tourism recreation, and carbon sequestration were estimated to remain relatively stable in terms of their capacity and demand. Carbon sequestration was considered to be the least important ES provided by urban GBI. Tourism recreation had the smallest gap between capacity and demand. However, participants agreed that mass tourism and the related demands for tourism recreation generated by GBI will affect the availability of and accessibility to green spaces. In turn, this situation would negatively affect the provision of other GBI-related benefits, including mental and physical recreation and social cohesion, all of which are derived from GBI through direct nature experiences (Bratman et al. 2019) and which appear to be more vulnerable to changes. Given the complexity of the resilience thinking exercise, consensus was difficult to reach in some cases, especially for assessing ES capacity. For instance, the group addressing the global warming scenario had diverging views on changes in capacity of regulatory services and gained consensus on "no changes" only after assuming that the current policies in place, including the Climate Action Plan, Green Infrastructure and Biodiversity Plan, and Tree Master Plan, will improve ES capacity. The group addressing the gender equality scenario did not arrive at a consensus over changes in capacity of social cohesion, mental well-being, and related relational benefits and recreational opportunities. Some participants were of the opinion that ES capacity will increase simply because women are excluded from daily use of the public space, whereas others opposed this idea. For the enhanced tourism scenario, some participants suggested that the ES capacity of recreational opportunities, tourism, and economic benefits will increase only in core urban areas because of new developments and emerging economic opportunities, whereas ES capacity will decrease in the city's outskirts.

\section{Adaptive policies to maintain ecosystem services potential}

To match an overall increased demand and uncertain capacity of ES, the policy measures proposed by participants can be summarized in two larger clusters. The first proposed policy measure was to include measures aimed at increasing and sustaining current GBI and the related capacity to generate regulating ES and cultural ES over time. The second was to include measures that would improve access to GBI for city inhabitants through a more inclusive and participatory design that would mitigate pressure on GBI, primarily through limiting the number of visitors, especially tourists. We summarized the linkages between the identified policy clusters, the three filters, the ES resilience principles, and the capacity and demand of cultural ES and regulating ES (Fig. 4).

Most of the greening measures proposed in the workshop included direct interventions in the current GBI and built infrastructure of the city, such as expanding GBI and further integrating green and grey infrastructures, and improving the quality of GBI by making it more socially and ecologically interconnected. It was suggested that greening and climate measures promote diversity and redundancy and increase the extent of GBI (Fig. 4). Suggested actions ranged from creating new green areas, increasing vegetation and biodiversity, developing sustainable urban drainage systems and permeable surfaces, and improving nodes and connectivity among different green areas. The measures suggested for mobility primarily focused on enhancing connectivity (principle 2) by means of redesigning sustainable and slow mobility to leave space for green areas, and improved integration of GBI and grey infrastructure. Also discussed was the importance of rethinking the role of the airport in the city, and limiting its further expansion.

Many of the policy interventions that were discussed target GBI through processes of maintenance and management rather than addressing GBI directly. Examples included involving citizens in urban transformation processes and projects to boost community care and maintenance of the GBI, as well as promoting relational and well-being aspects such as managing urban gardens. Urban planning is one of the guiding instruments at the core of institutions (Andersson et al. 2019), and many measures proposed refer to land-use rights, actor roles and responsibilities, and the different ways people can be involved in changing how land is planned for and used. Measures related to institutions and governance processes covered a range of options, such as a proposal to include technological innovations and greening 
Fig. 3. Assessment of the ecosystem services (ES) capacity and demand gaps in the four scenarios (S1 to S4). The darker shading indicates a decreasing trend in ES capacity $(-1=$ moderate decrease $;-2=$ substantial decrease), whereas the lighter shading indicates increasing demand for ES $(+1=$ moderate increase; $+2=$ substantial increase). The colored bars are averaged values from the ES assessment exercise, which highlight the majority of the respondents' opinions when consensus was not reached. Values equal to zero correspond to no changes in the ES capacity and demand assessment.

\begin{tabular}{|c|c|c|c|c|}
\hline S1: Aging and shrinking & -1 & 0 & 1 & \\
\hline \multicolumn{5}{|l|}{ Microclimate regulation } \\
\hline \multicolumn{5}{|l|}{ Runoff control } \\
\hline \multicolumn{5}{|l|}{ Air purification } \\
\hline \multicolumn{5}{|l|}{ Carbon sequestration } \\
\hline \multicolumn{5}{|l|}{ Noise reduction } \\
\hline \multicolumn{5}{|l|}{ Mental Wellbeing } \\
\hline \multicolumn{5}{|l|}{ Social cohesion } \\
\hline \multicolumn{5}{|l|}{ Physical recreation } \\
\hline \multicolumn{5}{|l|}{ Touristic recreation } \\
\hline S3: Gender inequalities & -1 & 0 & 1 & \\
\hline \multicolumn{5}{|l|}{ Microclimate regulation } \\
\hline \multicolumn{5}{|l|}{ Runoff control } \\
\hline \multicolumn{5}{|l|}{ Air purification } \\
\hline \multicolumn{5}{|l|}{ Carbon sequestration } \\
\hline \multicolumn{5}{|l|}{ Noise reduction } \\
\hline \multicolumn{5}{|l|}{ Mental Wellbeing } \\
\hline \multicolumn{5}{|l|}{ Social cohesion } \\
\hline \multicolumn{5}{|l|}{ Physical recreation } \\
\hline Touristic recreation & & & & \\
\hline
\end{tabular}

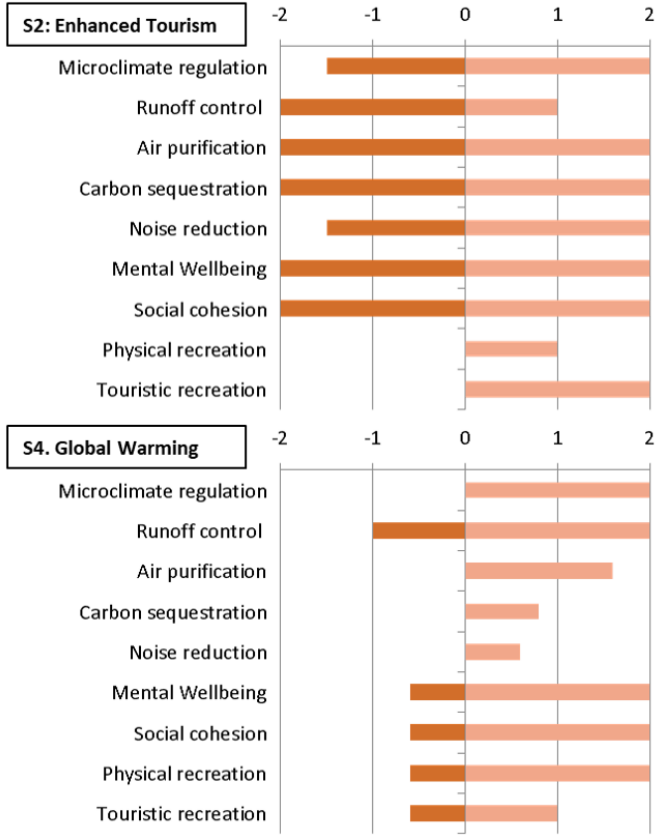

criteria as a requirement in building codes, mostly acting on regulating and cultural ES capacity (principles 1 and 2), but also increasing accessibility and inclusivity of existing green areas, including the security of those spaces (i.e., addressing cultural ES demand). A number of measures addressed the need to manage tourist flows so as to not overcrowd urban green areas, and to limit cultural ES demand in specific places in the city and its surrounding areas. Proposals addressing tourism included financial adjustments and suggestions to redirect tourism taxes to protection, maintenance, and improvement of green areas. Other proposals touched on greening, health, and including access to green areas in the annual health report as potential benefits for the human health of the city and managing slow variables and feedback (principle 3).

Another suggestion for the scenarios was to include the elderly and women in community initiatives for improving and maintaining local GBI (principles 1 and 6). Workshop participants also proposed measures for strengthening participation of vulnerable groups in GBI co-design, which would reframe both the physical space and how the urban environment is perceived (principle 6). Participants addressed perceptions in several other measures, which differed slightly from the respective scenarios. For example, urban farming was mainly addressed in the aging scenario and was recognized as a main factor enabling GBI benefits for the elderly, which confirms findings by CampsCalvet et al. (2016). In contrast, the gender inequalities scenario generated more attention to security (principles 1 and 6), improved accessibility (principles 1 and 6), and more inclusive codesign, co-management, and co-maintenance (principles 4, 5, 6, and 7). Feelings of insecurity and the unjust distribution of cultural ES benefits among different citizens groups were at the core of this discussion, which aligns with Maruthaveeran and van den Bosch (2014). Education (learning) and awareness-raising measures (principle 5) were mentioned as critical for involving different target groups (elderly, children, women, students) and mostly refer to environmental education activities.

\section{DISCUSSION}

Advancing multifaceted urban ecosystem resilience assessments The value of applying the urban ecosystem services resilience assessment matrix lies in the translation of theory into an analytical and operational framework for which we can assess urban policies, embracing the complexity of cities as adaptive social-ecological systems while helping to make them manageable (Table 1). Recognizing and connecting relevant system components is critical for building resilience (Biggs et al. 2012), and problem framing may serve as an indication of what solutions are being sought (e.g., Dennis and Brondizio 2020). For instance, applying the urban ecosystem services resilience assessment matrix to the sustainability policies of the city of Barcelona revealed a sophisticated incorporation of principles 1 and 2 mainly related to physical connectivity and consideration of biological diversity. Incorporating these principles would enhance the condition, accessibility, and connectivity of the urban GBI, 
Fig. 4. Linkages between the identified policy clusters, the three filters (Andersson et al. 2019), the ecosystem services (ES) resilience principles (P1 to P7; Biggs et al. 2012), and the capacity and demand of cultural ES (CES) and regulating ES (RES). The thicker lines represent stronger relationships and provide insights into the enabling effects of diverse policy options on ES resilient capacity and demand. SES = social-ecological system; CAS = complex adaptive system

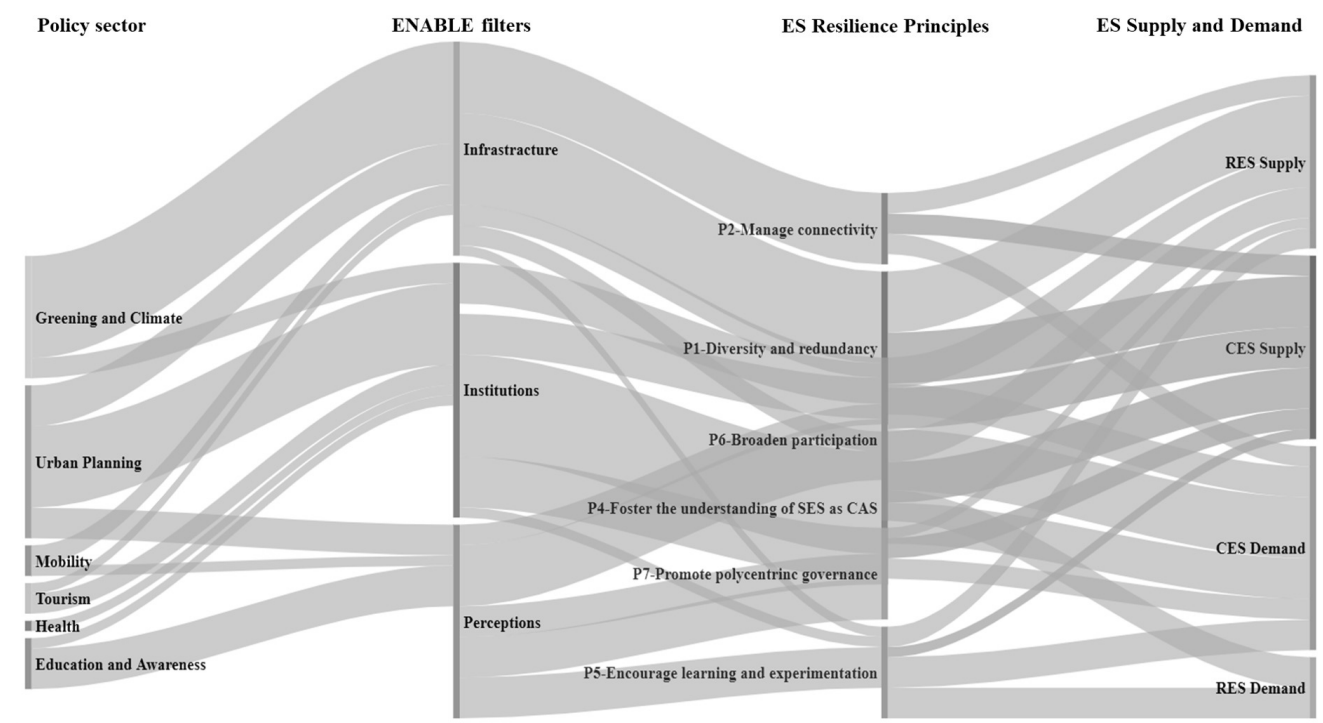

connecting biological diversity and also partly including the social and structural diversity of the urban GBI. Principles 6 and 7 are well embedded in current policies, indicating the city's growing interest in actively engaging its citizens and stakeholders in decision making processes and defining responsibilities, tools, and collaboration methods. Further, we found that scientific and technical knowledge of urban ES and GBI (principle 5) is well integrated into all of the policies, providing an entry point for science-driven approaches for addressing the existing gaps. Despite progressive incorporation of several crucial principles, other crucial aspects of urban diversity, such as social and structural diversity, are not properly addressed in the policies we assessed. Furthermore, none of the policies we analyzed had a clearly defined approach for identifying emergent signals, disturbances, or unforeseen changes, nor for potential respective responses (principles 3 and 4) Our study confirms observations by McPhearson et al. (2015) that urban ES are particularly valued in the context of climate adaptation, improved citizens' health and well-being, and as means for enhancing the city's resilience (resilience through urban ES). However, the resilience of urban ES ("resilience of what?") under changing conditions ("resilience to what?"), and possible changing demand ("resilience for whom?") (i.e., possible variables, disturbances, slow feedback, and changes) have yet to be adequately considered. Although the policies consider the potential effects of climate change on current GBI, application of the urban ecosystem services resilience assessment matrix can support a multilayered resilience assessment to tackle vulnerabilities to multiple external (e.g., pandemic, technological innovation) and inherent (e.g., demographic, lifestyle changes, housing, and socioeconomic) drivers of change.
Fostering resilience thinking: to what, of what, for whom?

Departing from the gaps identified in the policy assessment, and to elicit answers around our three main research questions ("resilience of what, to what, and for whom?"), the workshop participants were tasked with co-developing four future scenarios. The scenario exercise is at the interface of science and policy and in itself is a step to furthering resilience thinking (Pereira et al. 2019). After familiarizing themselves with the different future scenarios ("resilience to what?"), participants generally found it easiest to start with evaluating ES demands. Demand for cultural ES (i.e., citizen's needs) was assigned the highest importance and was the focus of most discussions, which is in line with the majority of urban ES studies that focus on (changing) ES capacity (Haase et al. 2014). Perceptions from a diversity of beneficiaries were explored (i.e., elderly, residents and tourists, and women) as well as potential changes in ES demand from vulnerable groups. Equal access and inclusively designed green spaces are considered crucial to address shifting ES demand in the future (e.g., Ode Sang et al. 2016, Fumagalli et al. 2020), not least to foster civic stewardship (Langemeyer et al. 2018, Andersson et al. 2019). Shifting ES demands and beneficiaries' perceptions were not prominent in the analyzed policies, suggesting that the codevelopment of the scenario on aging, gender, and tourism strongly supported resilience thinking toward this point ("resilience for whom?"). Although participants were instructed to work with a single scenario, they tended to consider different drivers, particularly mass tourism in conjunction with global warming. This tendency indicates the potential of stakeholder workshops for examining difficult problems of complex interacting external and inherent changes in relation to multiple ES demands, which can be difficult to capture through other approaches (e.g., computational modeling; Pereira et al. 2019, Scolozzi et al. 2019). Further, on the perception filter, the use of 
the scenario narratives helped participants to understand the potential changing needs of different groups of GBI users, and subsequently provided an improved understanding of current and future demand for ES. Scenario narratives supported not only stakeholders' understanding of the consequences of possible development paths ("resilience of what and to what?"; Nakicenovic and Zimm 2017), but also contributed to developing an inclusive vision for future sustainability ("resilience for whom?") and to proposing concrete policy adaptations for achieving sustainability (Palomo et al. 2011).

\section{Transdisciplinary co-creation toward adaptive sustainability policies}

The adaptive policy measures suggested during the workshop for tackling future ES capacity-demand mismatches embrace an understanding of the interconnected character of grey and green infrastructure in the city. The GBI and their different ecological qualities provide the first necessary precondition for ES (Andersson et al. 2019), including their maintenance and resilience over time. These strategies can be understood as promoting both the diversity of GBI (principle 1) and its connectivity (principle 2), which are two central aspects of ES resilience. Interestingly, several policy suggestions addressed transport and mobility, thus parts of the grey infrastructure, a sector that strongly affects the availability, or lack of, GBI benefits (Biernacka and Kronenberg 2019). In addition to making the structure of the GBI more resilient, the effects of human activity and the modification of urban ecosystems depend on good management and long-term governance to maintain or, in many cases, strengthen their ecological qualities. Interestingly, Amorim Maia et al. (2020) found in a recent study from Barcelona that aesthetically less-pleasing green spaces (those lacking monuments, fountains, with low quality of common GBI indicators) could lend to improved inclusivity and foster social inclusion, while mitigating social segregation. When asked to develop policy adaptations based on the identified shifts in ES capacity and demands, participants typically developed measures that touched on policy sectors such as mobility, tourism, and health.

Although it is widely recognized that urban planning decisions in sectors such as land use (Grêt-Regamey et al. 2017, Li et al. 2020), transport and mobility (Ghent 2018), and tourism (Taff et al. 2019) have a strong effect on ES capacity over time, the workshop results suggested that these changes also influence demand for ES. For instance, limiting air and port (cruise ships) traffic would lower the demand for cultural ES, and thus, the pressure on the current GBI; further, it would reduce air pollution and greenhouse gas emissions, thus reducing the need for urban GBI to provide these regulatory ES.

Furthermore, although the impacts of ES on human health and well-being are at the center of many studies, suggested measures also include improved long-term observation and monitoring of health benefits and the capacity of GBI to fulfill this need. The discussion elicited from the scenarios clearly showed that, on the institutional side, an integration beyond urban greening and planning is needed, including health, tourism, transport and mobility, and education and awareness. These sectors need to be connected to decision-making about land use and quality of life (Webster 2007, Bendt et al. 2013, Colding and Barthel 2013, Tozer et al. 2020). This conclusion points to the role of collaboration in fostering a cross-sector understanding of urban areas as complex social-ecological and adaptive systems, through enhanced crossscale approaches (principles 4 and 5). Thus, the role of institutions in enabling the flow of GBI benefits is not limited to urban planning, land-use policies, and building rights, but extends to other actors and policy sectors that become co-responsible enablers or inhibitors of GBI benefits in the city. In recognizing these linkages and using them to track performance over time, the policy measures and adaptations developed to enhance GBI and ES offer more concrete opportunities to increase the sustainability of the urban system as a whole, pointing toward sustainable and resilient trajectories (Elmqvist et al. 2019). Looking at beneficiaries' perceptions, and taking into account that GBI benefits are co-produced and that potential for realizing ES benefits is closely interrelated and shaped by the cultural and institutional context (Andersson et al. 2019), would improve the understanding of urban ES flow and benefits in the face of diverging ES demands and perceptions (see Riechers et al. 2016). This includes the proposal to develop mechanisms that support value creation and recognition of, for example, public land and the capacity of ES (principle 4).

Greater consideration of ES in other policy fields is needed and demanded. Applying the urban ecosystem services resilience assessment matrix to analyze the effects of policies from other sectors (e.g., housing, transport, health) to the urban GBI could also be explored in this light. The proposed scenarios also triggered reflections on uncertainty in planning while eliciting debate, and not always consensus, with regard to future ES resilience. This uncertainty warrants consideration of alternative and flexible approaches (principle 4; Walker et al. 2001) based on constant monitoring, evaluation, and revision, that are not fully addressed in current policies, but which were raised during the workshop (e.g., inclusion of green indicators into the annual health report).

\section{CONCLUSION}

Our study provides a tiered, transdisciplinary approach for engaging urban policy-making to foster adaptive resilience of and through urban ES. The approach consisted of assessing the city's baseline and trajectory for GBI and ES policy, developing possible future scenarios, and co-developing pathways to enhance adaptive capacities for urban policies. Application of the urban ecosystem services resilience assessment matrix for tailoring the ES resilience principles (Biggs et al. 2012) and integrating the three filters approach (Andersson et al. 2019) produced valuable results in the case study application, indicate that specific dimensions of ES capacity and demand are especially vulnerable to change, including microclimate regulation, water balances, mental wellbeing, and social cohesion.

The study revealed for the city of Barcelona an explicit need for fostering systemic, iterative resilience thinking and for considering multilayered processes of change and varied feedback loops. Analysis of current policies and plans revealed the city's current trajectory, with regard to sustainability goals, and highlighted the objectives for action that are needed to support a timely and sustainable urban transformation (Elmqvist et al. 2019). Overall, this research further elucidates the need for strengthening awareness and advancing learning among key 
urban stakeholders and planners regarding urban socialecological systems as complex adaptive systems. While a shared knowledge base strongly supported the stakeholder engagement process, given the participants' previous awareness and understanding of the topic $\mathrm{n}$ considering the diversity of experience and background of workshop participants, involving stakeholders from other policy fields and experts in sectors other than sustainability and resilience with diverse knowledge on GBI and ES topics would be beneficial for further exploring, investigating, and enhancing the role of institutional collaboration while also fostering an understanding of urban areas as complex social-ecological and adaptive systems (principle 4).

The process and application of theory to practice highlights the need for adaptive policies to focus not only on reshaping infrastructures, but to address institutions and perceptions, to be proactive in anticipating future needs and perceptions, and to develop new modes of decision making, co-creation, and comanagement of GBI. Based on adapting and applying the seven principles of resilience to the urban realm and connecting them with the three filters, we argue that adaptive policies (as an institutional tool) should shape current infrastructures with the aims of speaking to and reframing the perceptions of beneficiaries, while also acting preventively to anticipate future needs and perceptions. The use of the urban ecosystem services resilience assessment matrix in policy-making and planning, together with a participatory approach using scenario narratives, can function as a lens for understanding the city's trajectory with regard to sustainability and resilience, identifying leverage points in current policies for unlocking the flows of ES from nature to humans ("resilience of what"), dealing with uncertainties ("resilience to what"), and ensuring inclusivity ("resilience for whom").

Responses to this article can be read online at: https://www.ecologyandsociety.org/issues/responses. $\mathrm{php} / 12535$

\section{Author Contributions:}

Claudia de Luca developed the methods and performed the analysis presented in this work. She contributed to the development and the organization of the workshop and supported the development of the conceptual framework. She was responsible to draft and coordinate the writing work around the research paper. Johannes Langemeyer coordinated the whole process. He coordinated the development and organization of the workshop and the development of the conceptual framework. He edited and contributed to the writing of the paper. Simeon Vano contributed to the development and organization of the workshop. He also contributed to draft the methods and results sections. Francesc Baró coordinated the development and organization of the workshop. He edited and reviewed the paper. Erik Andersson supported the development of the conceptual framework. He edited and reviewed the paper.
}

\section{Acknowledgments:}

We would like to thank Ares Gabas Masip, Maria Gómez Llabrés and their team at the Barcelona's Urban Resilience Department, Myroslava Savisko for supporting the policy analysis, as well as Filka Sekulova, Luis Campos, Katriona McGlade and Andoni Gonzales Gomez for supporting the workshop moderation. This research was funded through the 2015-2016 BiodivERs A COFUND call for research proposals, by the national funders: the Swedish Research Council for Environment, Agricultural Sciences, and Spatial Planning, the Swedish Environmental Protection Agency, the German Aeronautics and Space Research Centre, the National Science Centre (Poland) (grant no. 2016/22/Z/NZ8/00003), the Research Council of Norway, and the Spanish Ministry of Economy and Competitiveness. It also received funding through the EU's Horizon 2020 framework program for research and innovation (project NATURVATION, grant agreement ID: 730243). JL acknowledges additional funding from the European Research Council (ERC Consolidator Grant: 818002-URBAG). FB's contributions were also supported by the European Research Council (project GREENLULUs; grant agreement ID: 678034). $C d L$ acknowledges additional funding from the Marco Polo scholarship supporting her visiting semester at ICTA-UAB. This research also contributes to the "María de Maeztu" Programme for Units of Excellence of the Spanish Ministry of Science and Innovation (CEX2019-000940-M) at ICTA-UAB.

\section{Data Availability:}

The data that support the findings of this study are openly available from Appendices 1 to 6 of the same study. More information can be available on request from the corresponding author.

\section{LITERATURE CITED}

Ahern, J., S. Cilliers, and J. Niemelä. 2014. The concept of ecosystem services in adaptive urban planning and design: a framework for supporting innovation. Landscape and Urban Planning 125:254-259. https://doi.org/10.1016/j.landurbplan.2014.01.020

Ajuntament de Barcelona. 2017. Trees for life : Master Plan for Barcelona's Trees 2017-2037. Àrea d'Ecologia Urbanisme i Mobilitat, Ajuntament de Barcelona, Barcelona, Spain. https:// bcnroc.ajuntament.barcelona.cat/jspui/handle/11703/102492

Ajuntament de Barcelona. 2014. Barcelona Green Infrastructure and Biodiversity Plan 2020. Direcció d'Espais Verds i Biodiversitat, Àrea d'Hàbitat, Ajuntament de Barcelona, Barcelona, Spain. https://hdl.handle.net/11703/85101

Ajuntament de Barcelona. 2018a. Climate Action Plan 20182030. Tinencia d'Alcaldia d'Ecologia, Urbanisme i Mobilitat, Àrea d'Ecologia, Gerència d'Ecologia Urbana, Adjuntament de Barcelona, Barcelona, Spain. http://hdl.handle.net/11703/109218

Ajuntament de Barcelona. 2018b. Barcelona: building a resilient city. Ecologia Urbana,Gerència Adjunta de Mobilitati Infrastructures, Department de Reiliencia Urbana, Ajuntament de Barcelona, Barcelona, Spain. [online] URL: http://ajuntament. barcelona.cat/ecologiaurbana/sites/default/files/ModelResilienciaBarcelona.pdf 
Amorim Maia, A. T., F. Calcagni, J. J. T. Connolly, I. Anguelovski, and J. Langemeyer. 2020. Hidden drivers of social injustice: uncovering unequal cultural ecosystem services behind green gentrification. Environmental Science and Policy 112:254-263. https://doi.org/10.1016/j.envsci.2020.05.021

Andersson, E., J. Langemeyer, S. Borgström, T. McPhearson, D. Haase, J. Kronenberg, D. N. Barton, M. Davis, S. Naumann, L. Röschel, and F. Baró. 2019. Enabling green and blue infrastructure to improve contributions to human well-being and equity in urban systems. BioScience 69(7):566-574. https://doi. org/10.1093/biosci/biz058

Andersson, E., M. Tengö, T. McPhearson, and P. Kremer. 2015. Cultural ecosystem services as a gateway for improving urban sustainability. Ecosystem Services 12:165-168. https://doi. org/10.1016/j.ecoser.2014.08.002

Barnaud, C., E. Corbera, R. Muradian, N. Salliou, C. Sirami, A. Vialatte, J.-P. Choisis, N. Dendoncker, R. Mathevet, C. Moreau, V. Reyes-García, M. Boada, M. Deconchat, C. Cibien, S. Garnier, R. Maneja, and M. Antona. 2018. Ecosystem services, social interdependencies, and collective action: a conceptual framework. Ecology and Society 23(1):15. https://doi. org/10.5751/ES-09848-230115

Baró, F., A. Calderón-Argelich, J. Langemeyer, and J. J. T. Connolly. 2019. Under one canopy? Assessing the distributional environmental justice implications of street tree benefits in Barcelona. Environmental Science and Policy 102:54-64. https:// doi.org/10.1016/j.envsci.2019.08.016

Baró, F., I. Palomo, G. Zulian, P. Vizcaino, D. Haase, and E. Gómez-Baggethun. 2016. Mapping ecosystem service capacity, flow and demand for landscape and urban planning: a case study in the Barcelona metropolitan region. Land Use Policy 57:405-417. https://doi.org/10.1016/j.landusepol.2016.06.006

Bendt, P., S. Barthel, and J. Colding. 2013. Civic greening and environmental learning in public-access community gardens in Berlin. Landscape and Urban Planning 109(1):18-30. https://doi. org/10.1016/j.landurbplan.2012.10.003

Biernacka, M., and J. Kronenberg. 2018. Classification of institutional barriers affecting the availability, accessibility and attractiveness of urban green spaces. Urban Forestry and Urban Greening 36(December):22-33. https://doi.org/10.1016/j.ufug.2018.09.007

Biernacka, M., and J. Kronenberg. 2019. Urban green space availability, accessibility and attractiveness, and the delivery of ecosystem services. Cities and the Environment 12(1). [online] URL: $\underline{\text { https://digitalcommons.lmu.edu/cate/vol12/iss1/5/ }}$

Biggs, R., M. Schlüter, D. Biggs, E. L. Bohensky, S. B. BurnSilver, G. Cundill, V. Dakos, T.M. Daw, L.S. Evans, K. Kotschy, A.M. Leitch, C. Meek, A. Quinlan, C. Raudsepp-Hearne, M.D. Robards, M.L. Schoon, L. Schultz, and P.C. West. 2012. Toward principles for enhancing the resilience of ecosystem services. Annual Review of Environment and Resources 37:421-448. https://doi.org/10.1146/annurev-environ-051211-123836

Borgström, S., Ö. Bodin, A. Sandström, and B. Crona. 2015. Developing an analytical framework for assessing progress toward ecosystem-based management. Ambio 44:357-369. https://doi.org/10.1007/s13280-015-0655-7
Bratman, G. N., C. B. Anderson, M. G. Berman, B. Cochran, S. de Vries, J. Flanders, C. Folke, H. Frumkin, J. J. Gross, T. Hartig, P. H. Kahn Jr., M. Kuo, J. J. Lawler, P. S. Levin, T. Lindahl, A. Meyer-Lindenberg, R. Mitchell, Z. Ouyang, J. Roe, L. Scarlett, J. R. Smith, M. van den Bosch, B. W. Wheeler, M. P. White, H. Zheng, and G. C. Daily. 2019. Nature and mental health: an ecosystem service perspective. Science Advances 5(7). https://doi. org/10.1126/sciadv.aax0903

Camps-Calvet, M., J. Langemeyer, L. Calvet-Mir, and E. GómezBaggethun. 2016. Ecosystem services provided by urban gardens in Barcelona, Spain: insights for policy and planning. Environmental Science and Policy 62:14-23. https://doi. org/10.1016/j.envsci.2016.01.007

Colding, J., and S. Barthel. 2013. The potential of 'urban green commons' in the resilience building of cities. Ecological Economics 86:156-166. https://doi.org/10.1016/j.ecolecon.2012.10.016

Cortinovis, C., and D. Geneletti. 2018. Ecosystem services in urban plans: what is there, and what is still needed for better decisions. Land Use Policy 70:298-312. https://doi.org/10.1016/j. landusepol.2017.10.017

Dennis, E. M., and E., Brondizio. 2020. Problem framing influences linkages among networks of collective action situations for water provision, wastewater, and water conservation in a metropolitan region. International Journal of the Commons 14(1):313-328. https://doi.org/10.5334/ijc.974

de Luca C., J. Martin, and S. Tondelli. 2021. Ecosystem services integration into local policies and strategies in the city of Bologna: analysis of the state of the art and recommendations for future development. Pages 127-139 in A. Arcidiacono and S. Ronchi, editors. Ecosystem services and green infrastructure: perspectives from spatial planning in Italy. Springer, Cham, Switzerland. https://doi.org/10.1007/978-3-030-54345-7 10

Eagles, P. F. J. 2014. Research priorities in park tourism. Journal of Sustainable Tourism 22(4):528-549. https://doi. org/10.1080/09669582.2013.785554

Elmqvist, T., E. Andersson, N. Frantzeskaki, T. McPhearson, P. Olsson, O. Gaffney, K. Takeuchi, and C. Folke. 2019. Sustainability and resilience for transformation in the urban century. Nature Sustainability 2(4):267-273. https://doi. org/10.1038/s41893-019-0250-1

Elmqvist, T. 2017. Development: sustainability and resilience differ. Nature 546:352. https://doi.org/10.1038/546352d

Ernstson, H. 2013. The social production of ecosystem services: a framework for studying environmental justice and ecological complexity in urbanized landscapes. Landscape and Urban Planning 109(1):7-17. https://doi.org/10.1016/j.landurbplan.2012.10.005

Fumagalli, N., E. Fermani, G. Senes, M. Boffi, L. Pola, and P. Inghilleri. 2020. Sustainable co-design with older people: the case of a public restorative garden in Milan (Italy). Sustainability 12 (8):3166. https://doi.org/10.3390/su12083166

Gascon, M., M. Triguero-Mas, D. Martínez, P. Dadvand, J. Forns, A. Plasència, and M. J. Nieuwenhuijsen. 2015. Mental health benefits of long-term exposure to residential green and blue 
spaces: a systematic review. International Journal of Environmental Research and Public Health 12(4):4354-4379. https://doi.org/10.3390/ijerph120404354

Geneletti, D., and L. Zardo. 2016. Ecosystem-based adaptation in cities: an analysis of European urban climate adaptation plans. Land Use Policy 50:38-47. https://doi.org/10.1016/j.landusepol.2015.09.003

Ghent, C. 2018. Mitigating the effects of transport infrastructure development on ecosystems. Consilience: The Journal of Sustainable Development 18(1):58-68. https://doi.org/10.7916/ consilience.v0i19.3892

Gómez-Baggethun, E., and D. N. Barton. 2013. Classifying and valuing ecosystem services for urban planning. Ecological Economics 86:235-245. https://doi.org/10.1016/j.ecolecon.2012.08.019

Grêt-Regamey, A., E. Sirén, S. H. Brunner, and B. Weibel. 2017. Review of decision support tools to operationalize the ecosystem services concept. Ecosystem Services 26(Part B): 306-315. https:// doi.org/10.1016/j.ecoser.2016.10.012

Güneralp, B., Y. Zhou, D. Ürge-Vorsatz, M. Gupta, S. Yu, P. L. Patel, M. Fragkias, X. Li, and K. C. Seto. 2017. Global scenarios of urban density and its impacts on building energy use through 2050. Proceedings of the National Academy of Sciences 114 (34):8945-8950. https://doi.org/10.1073/pnas.1606035114

Haase, D., N. Larondelle, E. Andersson, M. Artmann, S. Borgström, J. Breuste, E. Gomez-Baggethun, A. Gren, Z. Hamstead, R. Hansen, N. Kabisch, P. Kremer, J. Langemeyer, E. L. Rall, T. McPhearson, S. Pauleit, S. Qureshi, N. Schwarz, A. Voigt, D. Wurster, and T. Elmqvist. 2014. A quantitative review of urban ecosystem service assessments: concepts, models, and implementation. Ambio 43(4):413-433. https://doi.org/10.1007/ s13280-014-0504-0

Laarman, J. G., and H. M. Gregersen. 1996. Pricing policy in nature-based tourism. Tourism Management 17(4):247-254. https://doi.org/10.1016/0261-5177(96)00016-7

Langemeyer, J., and J. J. T. Connolly. 2020. Weaving notions of justice into urban ecosystem services research and practice. Environmental Science and Policy 109:1-14. https://doi. org/10.1016/j.envsci.2020.03.021

Langemeyer, J., I. Palomo, S. Baraibar, and E. Gómez-Baggethun. 2018. Participatory multi-criteria decision aid: operationalizing an integrated assessment of ecosystem services. Ecosystem Services 30(PartA):49-60. https://doi.org/10.1016/j.ecoser.2018.01.012

Langemeyer, J., D. Wedgwood, T. McPhearson, F. Baró, A. L. Madsen, and D. N. Barton. 2020. Creating urban green infrastructure where it is needed - a spatial ecosystem servicebased decision analysis of green roofs in Barcelona. Science of the Total Environment 707:135487. https://doi.org/10.1016/j. scitotenv.2019.135487

Larondelle, N., D. Haase, and N. Kabisch. 2014. Mapping the diversity of regulating ecosystem services in European cities. Global Environmental Change 26:119-129. https://doi. org/10.1016/j.gloenvcha.2014.04.008

Li, Z., X., Cheng and H. Han. 2020. Future impacts of land use change on ecosystem services under different scenarios in the ecological conservation area, Beijing, China. Forests 11(5):584. https://doi.org/10.3390/f11050584

Maruthaveeran, S., and C. C. K. van den Bosch. 2014. A socioecological exploration of fear of crime in urban green spaces - a systematic review. Urban Forestry and Urban Greening 13 (1):1-18. https://doi.org/10.1016/j.ufug.2013.11.006

McPhearson, T., E. Andersson, T. Elmqvist, and N. Frantzeskaki. 2015. Resilience of and through urban ecosystem services. Ecosystem Services 12:152-156. https://doi.org/10.1016/j. ecoser.2014.07.012

McPhearson, T., S. T. A. Pickett, N. B. Grimm, J. Niemelä, M. Alberti, T. Elmquist, C. Weber, D. Haase, J. Breuste, and S. Qureshi. 2016. Advancing urban rcology toward a science of cities. BioScience 66(3):198-212. https://doi.org/10.1093/biosci/ $\underline{\text { biw002 }}$

Meerow, S., J. P. Newell, M. Mendizabal, O. Heidrich, E. Feliu, G. García-Blanco, A. Mendizabal, S. T. A. Pickett, M. L. Cadenasso, J. M. Grove, B. McGrath, M. L. Cadenasso, A. J. Felson, A. Jansson, P. Romero-Lankao, D. M. Gnatz, O. Wilhelmi, and M. Hayden. 2004. Reaching for a sustainable, resilient urban future using the lens of ecosystem services. Renewable and Sustainable Energy Reviews 86(2):410-418.

Meerow, S., J. P. Newell, and M. Stults. 2016. Defining urban resilience: a review. Landscape and Urban Planning 147:38-49. https://doi.org/10.1016/j.landurbplan.2015.11.011

Moore, M. L., P. Olsson, W. Nilsson, L. Rose, and F.R. Westley. 2018. Navigating emergence and system reflexivity as key transformative capacities. Ecology and Society 23(2). https://doi. org/10.5751/ES-10166-230238

Moser, S., S. Meerow, J. Arnott, and E. Jack-Scott. 2019. The turbulent world of resilience: interpretations and themes for transdisciplinary dialogue. Climatic Change 153:21-40. https:// doi.org/10.1007/s10584-018-2358-0

Nakicenovic, N., and C. Zimm. 2017. Back to the future: the role of quantitative scenarios and narratives in understanding transformation to sustainability. Pages 23-34 in N. Dalhaus and D. Weißkopf, editors. Future scenarios of global cooperation practices and challenges. Käte Hamburger Kolleg/Centre for Global Cooperation Research. Duisburg, Germany. https://doi. org/10.14282/2198-0403-GD-14

Nelson, G. C., E. Bennett, A. A. Berhe, K. G. Cassman, R. Defries, T. Dietz, A. Dobson, A. Dobermann, A. Janetos, M. Levy, D. Marco, N. Nakicenovic, B. O’Neill, R. Norgaard, G. PetschelHeld, D. Ojima, P. Pingali, R. Watson, and M. Zurek. 2005. Drivers of change in ecosystem condition and services. Pages 173-214 in S.R. Carpenter, P.L. Pingali, E.M. Bennett, and M.B. Zurek, editors. Ecosystems and human well-being: scenarios, volume 2. Millenium Ecosystem Assessment. Washington, D.C., USA. [online] URL: https://www.millenniumassessment.org/ documents/document.331.aspx.pdf

Nykvist, B., S. Borgström, and E. Boyd. 2017. Assessing the adaptive capacity of multi-level water governance: ecosystem services under climate change in Mälardalen region, Sweden. Regional Environmental Change 17(8):2359-2371. https://doi. org/10.1007/s10113-017-1149-x 
Ode Sang, Å., I. Knez, B. Gunnarsson, and M. Hedblom. 2016. The effects of naturalness, gender, and age on how urban green space is perceived and used. Urban Forestry and Urban Greening 18:268-276. https://doi.org/10.1016/j.ufug.2016.06.008

Palomo, I., B. Martín-López, C. López-Santiago, and C. Montes. 2011. Participatory scenario planning for protected areas management under the ecosystem services framework: the Doñana social-ecological system in southwestern Spain. Ecology and Society 16(1):23. https://doi.org/10.5751/ES-03862-160123

Pereira, L., N. Sitas, F. Ravera, A. Jimenez-Aceituno, and A. Merrie. 2019. Building capacities for transformative change towards sustainability: imagination in intergovernmental sciencepolicy scenario processes. Elementa: Science of the Anthropocene 7:35. https://doi.org/10.1525/elementa.374

Priess, J. A., and J. Hauck. 2014. Integrative scenario development. Ecology and Society 19(1):12. https://doi. org/10.5751/ES-06168-190112

Quinlan, A. E., M. Berbés-Blázquez, L. J. Haider, and G. D. Peterson. 2016. Measuring and assessing resilience: broadening understanding through multiple disciplinary perspectives. Journal of Applied Ecology 53(3):677-687. https://doi. org/10.1111/1365-2664.12550

Riechers, M., J. Barkmann, and T. Tscharntke. 2016. Perceptions of cultural ecosystem services from urban green. Ecosystem Services 17:33-39. https://doi.org/10.1016/j.ecoser.2015.11.007

Romero-Lankao, P., D. M. Gnatz, O. Wilhelmi, and M. Hayden. 2016. Urban sustainability and resilience: from theory to practice. Sustainability (Switzerland). https://doi.org/10.3390/su8121224

Rozas-Vásquez, D., C. Fürst, D. Geneletti, and O. Almendra. 2018. Integration of ecosystem services in strategic environmental assessment across spatial planning scales. Land Use Policy 71:303-310. https://doi.org/10.1016/j.landusepol.2017.12.015

Schewenius, M., T. McPhearson, and T. Elmqvist. 2014. Opportunities for increasing resilience and sustainability of urban social-ecological systems: insights from the URBES and the cities and biodiversity outlook projects. Ambio 43:434-444. https://doi. org/10.1007/s13280-014-0505-Z

Schröter, M., E. H. van der Zanden, A. P. E. van Oudenhoven, R. P. Remme, H. M. Serna-Chavez, R. S. de Groot, and P. Opdam. 2014. Ecosystem services as a contested concept: a synthesis of critique and counter-arguments. Conservation Letters 7 (6):514-523. https://doi.org/10.1111/conl.12091

Scolozzi, R., T., Schirpke, D., Geneletti. 2019. Enhancing ecosystem services management in protected areas through participatory system dynamics modelling. Landscape Online 73:1-17. https://doi.org/10.3097/LO.201973

Sellberg, M. M., P. Ryan, S. T. Borgström, A. V. Norström, and G. D. Peterson. 2018. From resilience thinking to resilience planning: lessons from practice. Journal of Environmental Management 217:906-918. https://doi.org/10.1016/j.jenvman.2018.04.012

Simon, D., C. Griffith, and H. Nagrenda. 2018. Rethinking urban sustainability and resilience. Pages 149-162 in T. Elmqvist, X. Bai, N. Frantzeskaki, C. Griffith, D. Maddox, T. McPhearson, S.
Parnell, P. Romero-Lankao, D. Simon, and M. Watkins, editors. 2018. The urban planet-knowledge towards sustainble cities. Cambridge University Press, Cambridge, UK. https://doi. org/10.1017/9781316647554

Taff, B. D., J. Benfield, Z. D. Miller, A. D'antonio, and F. Schwartz. 2019. The role of tourism impacts on cultural ecosystem services. Environments - MDPI 6(4):1-12. https://doi. org/10.3390/environments6040043

Tozer, L., K. Hörschelmann, I. Anguelovski, H. Bulkeley, and Y. Lazova. 2020. Whose city? whose nature? towards inclusive nature-based solution governance. Cities 107:102892. https://doi. org/10.1016/j.cities.2020.102892

United Nations, Department of Economic and Social Affairs, Population Division. 2019. World urbanization prospects: the 2018 revision (ST/ESA/SER.A/420). United Nations, New York, New York, USA. [online] URL: https://population.un.org/wup/ Publications/Files/WUP2018-Report.pdf

van den Berg, M., W. Wendel-Vos, M. van Poppel, H. Kemper, W. van Mechelen, and J. Maas. 2015. Health benefits of green spaces in the living environment: a systematic review of epidemiological studies. Urban Forestry and Urban Greening 14 (4):806-816. https://doi.org/10.1016/j.ufug.2015.07.008

Villamagna, A. M., P. L. Angermeier, and E. M. Bennett. 2013. Capacity, pressure, demand, and flow: a conceptual framework for analyzing ecosystem service provision and delivery. Ecological Complexity 15:114-121. https://doi.org/10.1016/j.ecocom.2013.07.004

Walker, W. E., S. A. Rahman, and J. Cave. 2001. Adaptive policies, policy analysis, and policy-making. European Journal of Operational Research 128(2):282-289. https://doi.org/10.1016/ $\underline{\mathrm{S} 0377-2217(00) 00071-0}$

Webster, C. 2007. Property rights, public space and urban design. Town Planning Review 78(1):80-101. https://doi.org/10.3828/ tpr.78.1.6

Wiese, F. 2016. Resilience thinking as an interdisciplinary guiding principle for energy system transitions. Resources 5(4):30. https:// doi.org/10.3390/resources5040030 


\section{Appendix 1}

Urban ecosystem services resilience assessment matrix. Criteria for assessing expressions of ES resilience thinking in policies regarding GBI in urban context (authors adaptation, based on Borgström et al 2015, and Nykvist et al 2017, Biggs et. a, 2012)

\begin{tabular}{|c|c|c|c|}
\hline $\begin{array}{l}\text { ES resilience } \\
\text { aspects }\end{array}$ & $\begin{array}{l}\text { Specification/Guiding questions for the } \\
\text { assessment }\end{array}$ & Qualitative evaluation criteria & $\begin{array}{l}\text { Relation to } \\
\text { Biggs } \\
\text { Resilience } \\
\text { principle }\end{array}$ \\
\hline $\begin{array}{l}\text { Diversity } \\
\text { consideration }\end{array}$ & $\begin{array}{l}\text { Biological diversity: } \\
\text { How are genetic, species and landscape } \\
\text { level diversity addressed? } \\
\text { How are interactions between species } \\
\text { and/or ecological succession } \\
\text { addressed? } \\
\text { How is complementarity in the } \\
\text { landscape addressed? } \\
\text { Social diversity: } \\
\text { How are the different socio-economic } \\
\text { components of the urban areas } \\
\text { analyzed? } \\
\text { How are cultural and historical values } \\
\text { considered? } \\
\text { Structural diversity: } \\
\text { How is urban structure (in terms of } \\
\text { neighbourhoods' differences and } \\
\text { components) considered? } \\
\text { Spatial/temporal scale is considered? }\end{array}$ & $\begin{array}{l}\text { High: All the components are addressed in detail. } \\
\text { Biodiversity is addressed at genetic and species level; } \\
\text { different relations in the system (e.g., food webs) are } \\
\text { described as well as essential processes (e.g., nutrient } \\
\text { cycling, hydrology); well consideration of different } \\
\text { social groups, their current or potential employment } \\
\text { rates, housing characteristics, growing population, and } \\
\text { increasing immigration is taken into account in spatial } \\
\text { and temporal scales; considered differences of } \\
\text { neighbourhood/district characteristics } \\
\text { Medium: several components of biodiversity in terms } \\
\text { of species are addressed; no detailed reference to the } \\
\text { different relation in the system. growing population } \\
\text { and increasing immigration is mentioned without } \\
\text { spatial or temporal scales, some information about } \\
\text { different social groups and their employment rates are } \\
\text { mentioned. No clear division in districts' } \\
\text { characteristics } \\
\text { Low: no components of biodiversity in terms of species } \\
\text { are addressed; no reference to the different relations in } \\
\text { the system. rowing population and increasing } \\
\text { immigration not addressed or very vague. no reference } \\
\text { do the spatial component of the socio economic and } \\
\text { demographic characteristics }\end{array}$ & $\mathrm{P} 1, \mathrm{P} 4$ \\
\hline $\begin{array}{l}\text { Use of } \\
\text { different } \\
\text { knowledge } \\
\text { spheres }\end{array}$ & $\begin{array}{l}\text { What kind of knowledge is used? } \\
\text { How is involvement of different } \\
\text { stakeholders in planning, design, } \\
\text { management, monitoring etc. } \\
\text { addressed? } \\
\text { Spatial/temporal scale is considered? }\end{array}$ & $\begin{array}{l}\text { High: Different kind of knowledge have been used (i.e } \\
\text { reference to scientific framework or existing studies, } \\
\text { informal knowledge, previously acquired knowledge); } \\
\text { detailed explanation and presentation of the } \\
\text { stakeholders to be included in the different steps, } \\
\text { collaboration pathways and different role clearly } \\
\text { explained. } \\
\text { Medium: Knowledge-base is not completely clear; } \\
\text { some references to previous study but not }\end{array}$ & P1, P5, P6 \\
\hline
\end{tabular}


Physical connectivity

\section{Disturbance regimes}

How is green and blue infrastructure (structures, nodes, networks, species migration etc.) addressed?

How is mobility and physical accessibility addressed? Spatial/temporal scale is considered?
How is information flow addressed?

comprehensive assessment of the knowledge sphere included. Stakeholders presented in different details, collaboration mentioned, but not clear roles and methods

Low: Knowledge base is fuzzy and not references. Not clear reference to stakeholders either to roles and methods of collaboration

High: Map of the existing blue and green infrastructure presented, evaluated and used as a base for further discussion on the topics; existing nodes, networks, and possibilities for species migration have been addressed. Concrete actions agreed and well presented to improve current infrastructures connectivity. Accessibility to the green and blue infrastructure is assessed and well considered. Physical nodes and mobility and transport scheme have been previously assessed and the results are integrated in the policy. Actions on how to improve it are considered.

Medium: reference to the overall green infrastructure present but not clear the level of detail; existing nodes, networks and species migration mentioned; mention to future development of the structures, but no concrete actions mentioned. Accessibility to the spaces is considered but not detailed explained neither in present or future actions

Low: reference to the overall green infrastructure present but not clear the level of detail; existing nodes, networks and species migration not mentioned; no mentions of future development of the structures. accessibility and connectivity are not consider neither as an assessment neither for future development

What disturbances are recognized?

High: disturbances have been identified and assessed with clear reference to spatial and temporal frame. Responses to disturbances have been clearly identified (i.e. action plans, strategy, etc.)- specify which disturbances and responses have been considered

Medium: main disturbances have been identified, but there's no clear spatial and temporal frame. Responses to disturbances have also been considered, but not clear actions planned - specify which disturbances and responses have been considered

Low: disturbances have not been identified, neither clear responses to possible events 
Assessment of What changes are recognised, e.g. High: main possible changes trend and scenario P3, P4

forecast, possible climate, demographical, economic, relevant for the city development and planning have

changes and political, technological innovation, been considered, they have been integrated and

uncertainty human preferences and lifestyle (CES), overlapped among them; monitoring, evaluation and tourism, housing, land use planning? revision methods and actions have been addressed.

Are changes in relation with future Possible changes in ES capacity and demand have capacity and demand of ES considered been addressed, even if not explicitly mentioned as and addressed?

such.

How are monitoring, evaluation and Medium: main possible changes, trend and scenario revision addressed? have been considered, with low level of detail and no

Spatial/temporal scale is considered? integration among them; monitoring, evaluation and revision are mentioned but not explained in detail. Possible changes in ES capacity and demand are not clearly addressed, even if not explicitly mentioned as such.

Low: main possible changes trend and scenario have not been considered, maybe mentioned but not assessed; no reference to monitoring evaluation and revision. Possible changes in ES capacity and demand are not addressed, neither implicitly.

\section{System}

knowledge approach

Institutional flexibility

Poly centric governance
How are the management steps of High: management steps of monitoring, evaluating, monitoring, evaluating, revising and adapting addressed?

revising and adapting are well addressed. Responses to changes as well as emergent signals are well defined and integrated.

How are emergent signals captured?

How are responses to changes Medium: management steps of monitoring, evaluating, addressed? revising and adapting are mentioned, but not clearly addressed as well as emergent signals. Responses to changes are not clearly defined and integrated.

Low: no specific management steps of monitoring, evaluating, revising and adapting are mentioned neither emergent signals are addressed. Responses to changes are not defined and integrated.

In what ways is the approaches to GBI High: alternative approaches are considered and clea reactive or proactive? criteria for decision support are recognized. High

How are alternative approaches recognized? degree of flexibility of the policy is recognized and structured.

What kind of formulations are used, e.g. Medium: alternative approaches are recognized, bit not shall, should, recommend? clear criteria to support decision are recognized. Flexibility and adaptation of the policy are considered but not addressed.

Low: alternative approaches are not recognized; possible flexibility of the policy has not been considered

How is governance organised High: multi-stakeholders and participatory process have

(centralised/decentralised, single been set up from the policy development and have

$\mathrm{P} 3, \mathrm{P} 4, \mathrm{P} 5$

(1)


actor/multiple actors, sector divided, strong/weak linkages across levels, sectors and actors)?

How is collaboration between actors addressed?

How is responsibility organised? been integrated in the strategy/action plans for future collaboration. Governance models are clearly defined and flexible. Responsibility and roles are also well explained. Collaboration among stakeholders is well defined; dedicated tools instruments and methods have been developed.

Medium: multi-stakeholders and participatory process have been set up but not clearly integrated and explained in the overall process. Governance models are defined but with low level of details. Roles, responsibilities and competences are implicitly considered but not clearly defined in the text. Collaboration among stakeholders is mentioned but dedicated tools instruments and methods are not clearly defined. Low: multi-stakeholders and participatory process are not integrated and explained in the overall process. Governance models, responsibility and roles are fuzzy and not clearly identified. Not clear how stakeholders will cooperate 


\section{Appendix 2}

Barcelona relevant policies analysed in the context of this study

\begin{tabular}{|c|c|}
\hline $\mathrm{N}$ & Name of the relevant document \\
\hline 1 & $\begin{array}{l}\text { Ajuntament de Barcelona. Àrea d'Ecologia Urbanisme i Mobilitat. 2015. "Guide to Living } \\
\text { Terrace Roofs and Green Roofs." }\end{array}$ \\
\hline 2 & $\begin{array}{l}\text { Ajuntament de Barcelona. Àrea d'Ecologia Urbanisme i Mobilitat. 2017. "Trees for Life : } \\
\text { Master Plan for Barcelona's Trees } 2017 \text { - 2037." }\end{array}$ \\
\hline 3 & Ajuntament de Barcelona. 2014. "Plan Del Verde y de La Biodiversidad de Barcelona 2020." \\
\hline 4 & $\begin{array}{l}\text { Ajuntament de Barcelona. 2018a. Departament de Resiliència Urbana, Gerència d'Ecologia } \\
\text { Urbana, } 100 \text { Resilient Cities (Associació) "Barcelona : Preliminary Resilience Assessment." }\end{array}$ \\
\hline 5 & Ajuntament de Barcelona. 2018b. "Pla Clima 2018-2030." \\
\hline 6 & $\begin{array}{l}\text { PGM/PGU - Metropolitan Planning regulation of the general plan - "PDU- QUADERNS } \\
\text { PDU METROPOLITÀ } 03 \text { - Urbanism of open spaces: landscape, leisure and production }\end{array}$ \\
\hline 7 & $\begin{array}{l}\text { Ajuntament de Barcelona 2018. Pla estratègic dels espais litorals de la ciutat - under } \\
\text { development }\end{array}$ \\
\hline 8 & $\begin{array}{l}\text { Ajuntament de Barcelona 2015, Comissió d'Hàbitat Urbà i Medi Ambient, Gerència Adjunta } \\
\text { de Medi Ambient i Serveis Urbans, Àrea d'Hàbitat Urbà Pla de millora de la qualitat de l'aire } \\
\text { de Barcelona 2015-2018 }\end{array}$ \\
\hline 9 & $\begin{array}{l}\text { Milan Urban Food Policy Pact, Ajuntament de Barcelona, 2015. Pacto de Milán de política } \\
\text { alimentaria urbana }\end{array}$ \\
\hline 10 & $\begin{array}{l}\text { Ajuntament de Barcelona 2016. Omplim de vida els carrers, la implantació de les superilles } \\
\text { a Barcelona : mesura de govern- The superblock plan }\end{array}$ \\
\hline
\end{tabular}




\section{Appendix 3}

List of participants to the workshop

\begin{tabular}{|l|l|l|}
\hline $\mathrm{N}^{\mathbf{o}}$ & Affiliation & Sector \\
\hline 1 & $\begin{array}{l}\text { Institute of Environmental Science and Technology (ICTA), } \\
\text { Universitat Autònoma de Barcelona (UAB), (organizer) }\end{array}$ & Research \\
\hline 2 & $\begin{array}{l}\text { Ajuntament de Barcelona, Departamento de Resiliencia } \\
\text { Urbana (co-organizer) }\end{array}$ & Public Administration \\
\hline 3 & Alma Mater Studiorum - Università di Bologna (co-organizer) & Research \\
\hline 4 & ENT, medi ambient i gestió (co-organizer) & SME \\
\hline 5 & Ecologic Institute (co-organizer) & Research \\
\hline 6 & 100 resilient cities & Research \\
\hline 7 & Generalitat de Catalunya - DTES & Public Administration \\
\hline 8 & Àrea Metropolitana de BarcelonaAMB & Public Administration \\
\hline 9 & Diputació de Barcelona & Public Administration \\
\hline 10 & Suez & Industry \\
\hline 11 & LEITAT & Research and Innovation \\
\hline 12 & Universitat Oberta de Catalunya & Research \\
\hline 13 & $\begin{array}{l}\text { Agència de Salut Pública de Barcelona - Generalitat de de } \\
\text { Catalunya }\end{array}$ & Public Administration \\
\hline 14 & Cátedra UNESCO de Sostenibilidad- & Research \\
\hline 15 & Universitat Politècnica de Catalunya - UPC-BarcelonaTech & Research \\
\hline 16 & Universitat Internacional de Catalunya UIC & Research \\
\hline 17 & Fàbrical del Sol & $\begin{array}{l}\text { Public Administration } \\
\text { environmental education centre }\end{array}$ \\
\hline 18 & Som Natura & NGO - civil society \\
\hline 19 & Elrisell & SME Consultancy \\
\hline 20 & Eix Verd & SME Social enterprise \\
\hline 21 & Oficina Catalana del Canvi Climàtic & $\begin{array}{l}\text { Public Administration and } \\
\text { research }\end{array}$ \\
\hline 22 & Barcelona Cicle de l'Aigua SA (BCASA) & Public Administration \\
\hline 23 & Agència de Salut Pública de Barcelona & Public Administration \\
\hline 24 & Universitat de Màlaga & Public Administration \\
\hline 25 & Barcelona Regional & Public Administration \\
\hline 26 & Ajuntament de Sabadell & NGO - civil society \\
\hline 27 & Huertosinthesky & (a) \\
\hline
\end{tabular}




\section{Appendix 4}

\section{Ecosystem services assessment workshop exercise}

\section{Objectives}

This exercise aims to reveal potential shifts in the demand and supply of ES exposed by the scenarios - possible futures.

\section{Materials}

Scenario print-outs 50x (10x4 for participants $+2 \times 4$ for moderators); Printed images 12x (3 per scenario); Impact assessment poster 4x (1 per group); Sticky points 40x (10 per group); Markers in different colors 16x (poster operations)

\section{Description}

After the introducing presentation by Johannes and Claudia, participants are divided into 3 or 4 heterogeneous groups to work independently on the assigned scenario (1 per group). Each group is formed by the maximum number of 10 participants (depending on the final list of participants). Group sessions are operated by the facilitator and the note-taker (1 and 1 per group). The facilitator presents the scenario (5min), supported by the images placed on the table and printed scenario materials, including bullet points as a summary.

Each group will then start to work on the ES impact assessment (Figure 1), represented by selected list of ES (icons) placed on the scale. Participants are asked to assess the shifting ES supply/demand reflecting on the presented scenario. Each group receives sticky points (one per ES to be assessed + 1 extra sticky point for potential suggestions of different ES by participants) that are used to indicate the shifting supply/demand for selected ES (by participants). If no consensus is made within a group on the placement of certain ES on the scale (which ES and how they shift), moderator will start the voting.
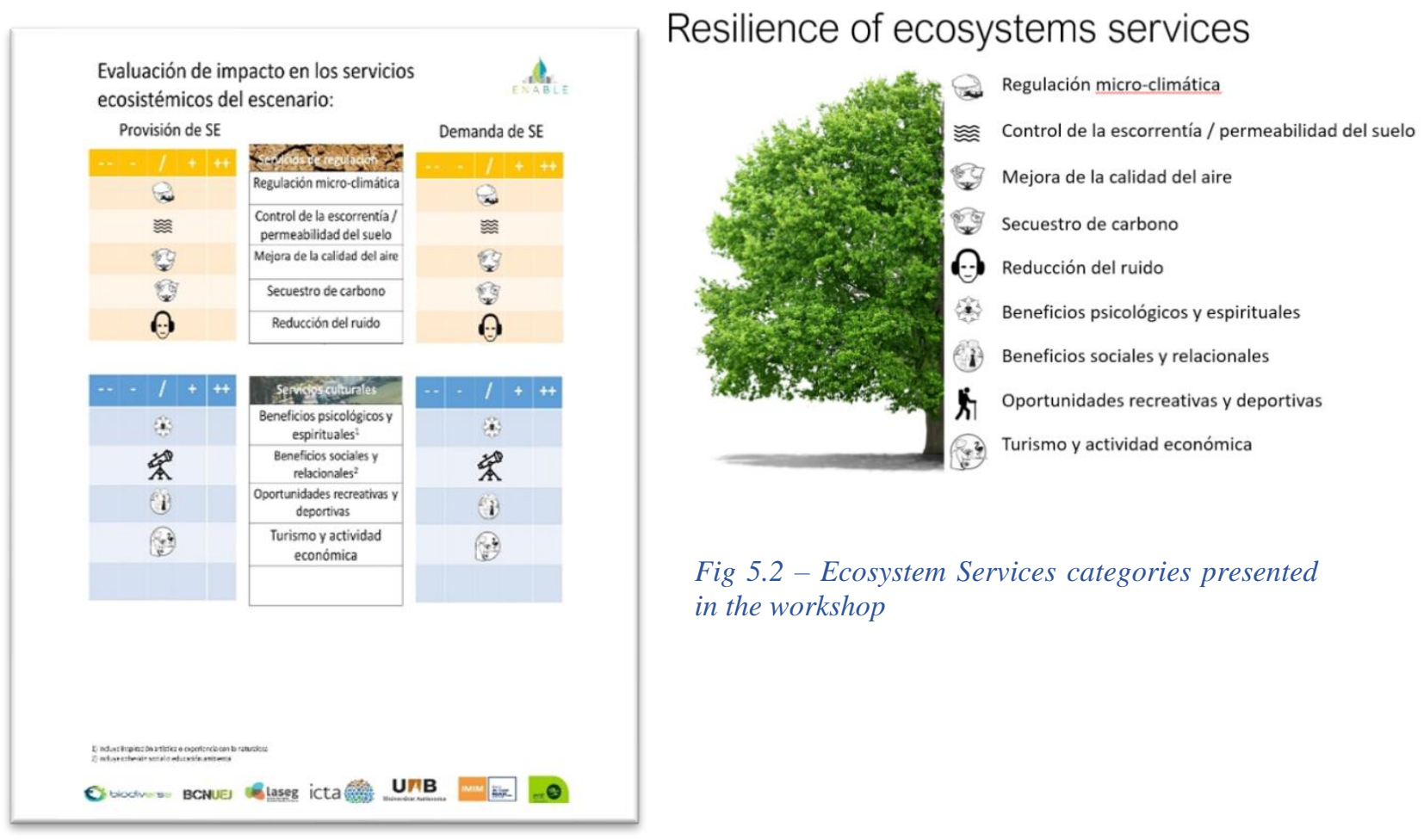

Fig 5.2 - Ecosystem Services categories presented in the workshop

Fig 5.1 - Ecosystem Services impact assessment poster used in the workshop poster 


\section{Appendix 5}

\section{Policy options workshop exercise}

\section{Objectives}

This part aims at understanding how current policies and strategies can work to ensure the ES provisions in the long-term perspective - by discovering resilient policy options.

\section{Materials}

Post-its 40x and pens 40x (the individual exercise); Policy development poster 4x (1 per group); Markers in different colors 16x (poster operations)

\section{Description}

Participants will be asked to individually reflect on the ES impact assessment within the given scenario, and to propose a policy-oriented action (the same groups are maintained). First, each participant receives one post-it from the facilitator. Then, participants are asked to write their name and the acronym of the organization they belong to on their post-it (this will allow facilitators to understand if there are certain 'clusters' of stakeholders). This exercise is individual (5min), where participants are asked the following reflection remark:

"Please indicate the ES that you consider as most important to be addressed. Name one measure that you find most promising in order to guarantee the future supply of ES under the scenario of change you worked with."

After the individual exercise, participants briefly present their ideas one by one. Meanwhile, moderator collects filled post-its and start to cluster the written ideas on the poster (Figure 2) according to common features (i.e. addressed policy sectors, addressed ES, etc.) (10 minutes). When the brief presentations are over, and all ideas are placed on the flipchart, moderator triggers the discussion among the participants referring to collected ideas (30 minutes). The discussion is directed by the following reflection remarks:

"How can the measures be integrated into existing policies. What themes, sectors, and policies are most relevant to be addressed? What policy action/intervention would you propose to improve "resilience" of current policies?"

During the discussion, moderator keeps incorporating the new ideas and observations in the poster - as these may arise. This is done by operating with the marker and by replacing around the post-its.

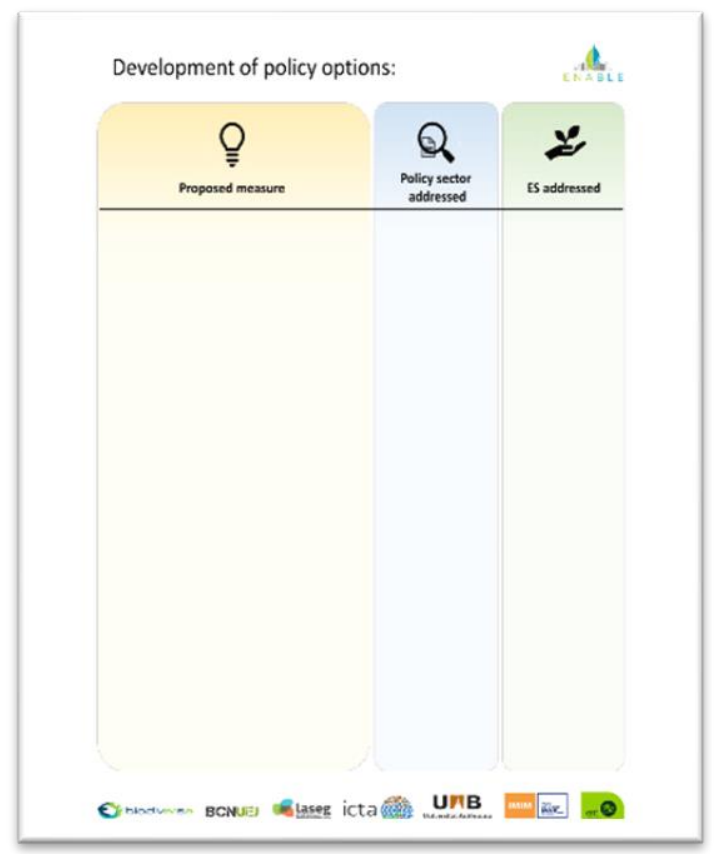

Fig. 6.2 Policy options poster 


\section{Appendix 6}

\section{Scenario Narratives}

\section{1\# Scenario: Ageing and shrinking population}

\section{(moderator: Claudia de Luca, notes: Katriona McGlade)}

- Barcelona 2025; outmigration of young population and ageing of resident population emerged as main issues.

- The pressures on health, mobility, housing, job availability, and social services have substantially increased.

- Elders suffer high levels of depression and loneliness, lacking opportunities to engage (socially or economically), and in public health and wellbeing.

- City is lacking accessible open green spaces, as these have capacity to provide manifold social and environmental benefits.

Barcelona 2025; As a consequence of the climate and economic crisis in the last 15 years, the city lost around 200.000 inhabitants, mostly young educated people, resulting in a resident population of around 1.4 million ${ }^{1}$. Also, birth rate has decreased substantially over the period, as young people continue facing serious barriers in access to secure jobs and affordable housing, with direct consequences on household formation and natality levels.

As a matter of fact, elderly people account now for over $27 \%$ of the resident population (compared to $21 \%$ in 2016 ) generating an increased pressure on urban systems, such as health, mobility and social services among others. In terms of household composition, this is resulting in an increasing number of elderly people living alone, as well as in new and crowded retirement homes managed by the City Council, private entities and third sector organisations. The Agència de Salut Pública de Barcelona (ASPB) reports that depression rates especially among the elderly population are becoming alarming, calling for concrete actions to address the challenges of ageing population in an integrated way.

Within this context, scientific evidences on the positive links between health, social interaction, and green public spaces, are becoming increasingly acknowledged by policy-makers with competencies over public health, seeking to foster the use of green and public spaces by local population, especially elderly people. However, in a high-density urban area, with limited space for urban regeneration and rapidly changing demographic patterns, these efforts require integrated and creative solutions across several policy areas.

\section{2\# Scenario: Enhanced tourism}

(moderator: Maria Gómez, notes: Luis Campos)

- Barcelona 2025; mass tourism is a source of wealth but also of complex challenges.

- The pressures on housing, services, and urban space availability as well as on urban environment have substantially increased.

- This has resulted in rising prices, increase in illegal activities, overcrowded and degraded open spaces, and in changing attitudes of residents living in affected central neighbourhoods.

- Affected residents are deprived of available green spaces and beaches for recreation. Several local movements have emerged and started to act.

- Policy interventions are needed in order to re-establish the availability open spaces and related benefits, fostering the wellbeing of residents.

Barcelona in 2025; tourism further increased. The city now received more than 30million annual visits, in average more than 160,000 per day ${ }^{2}$. Hospitality business and related tourism offers have grown substantially. Tourism belongs to the most important economic activities in Barcelona, providing income to a large share of the residents. Nevertheless, the negative impacts of tourism are being progressively questioned.

\footnotetext{
${ }^{1}$ http://www.bcn.cat/estadistica/angles/dades/tpob/projeccions/pob/prpob/base2013/bcn/t111.htm

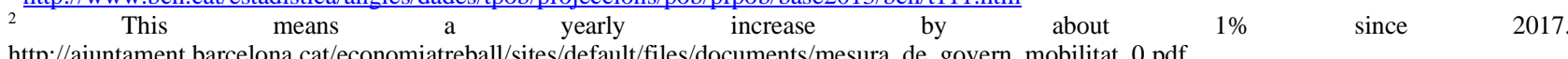


From an environmental point of view ${ }^{3}$ - carbon footprint, water usage, waste disposal - mass tourism is hardly sustainable in a very compact and dense city as Barcelona. From a social point of view, attitude of some resident groups has drastically changed in the last 15 years.

As from 2015, the city council has started developing measures to regulate mass tourism (e.g. diversifying offers, licence limitation, tourism taxation, etc.). Nevertheless, it did not prove to be effective on some of the main issues: housing prices (20\% rise in central neighbourhoods), public transport, and especially access to open spaces and cultural sites Barceloneta beach, Ciutadella, Parc Guell, Mont Juic, public squares and ramblas. Also, a trend of 'urban nature tourism' emerges, flooding parks in Barcelona with birdwatchers, picknickers, beerdrinkers.

The wellbeing of residents has suffered, as they are deprived of the beneficiary effects coming from the nature experience. Also, affected green spaces are now subjects of degradation. Residents started to avoid using these green spaces and beeches, as they are overcrowded and noisy.

An integrated policy action is needed in order to foster the social life, to enable access to recreation in the city, and to improve health and wellbeing of its citizens.

\section{3\# Scenario: Gender inequality}

(moderator: Johannes Langemeyer, notes: Filka Sekulova)

- Barcelona 2025; Public spaces are dominantly used by male population due to certain changes in perceptions and behaviours. Equal access to green and open public spaces is questioned and gender issues are increasingly raising.

- An increasing number of women is reporting negative experiences from their visits of open spaces, also due to misperception and disinformation. The "stories" are spreading fast.

- The access to green spaces by women became limited, as they perceive them as unsafe.

- In result, the female population is deprived of benefits related with urban nature.

- Policy interventions are needed to re-establish the accessibility to open spaces and related benefits.

Barcelona in 2025. the number of visits to green spaces by female population has declined in the last years, resulting in more "homogenized" male-oriented user groups. This trend emerged as a product of changing behaviours and perceptions of public spaces in Barcelona, especially among women. Some serious questions related to gender equity have been put forth.

Negative experiences, including ambushes, thievery, sexual harassment, and other dangerous encounters have been reported, whereas the victims are being predominantly women. Even though these encounters are rather rare, the stories continue to spread. The public community, and specifically women, widely perceive the open spaces as unsafe. Especially larger green spaces that are difficult to control, such as Collserola, Montjuic, Park Güell, or Tres Turons, are evoking negative thoughts and anxiety. Besides female population, families and elderly have started to avoid these areas too.

The accessibility to nature experience in the city has become limited as the feeling of safeness has dropped extremely. Changing perceptions further affect behaviours; concerned user groups (mostly women and elderly) are feeling threatened, what induces their suspicious behaviour and tendency to avoid social encounters in the public spaces. Social interactions and gender equity are disrupted. In fact, green spaces are considered by women to be the most unsafe urban areas $^{4}$, due to crime and violence that they are exposed to.

Female users are deprived of the benefits linked to the green space use as result of realities narrated above. To re-establish social equity in terms of the opportunities to experience urban nature for all, policy interventions will be necessary.

\section{4\# Scenario: Global warming \\ (moderator: Francesc Barò, notes: Andoni Gonzales)}

- Barcelona 2025; climate change has intensified and is affecting the city and its residents.

- Increase in the number of torrid days, droughts, fires, rain-shortages, and water scarcity represent and immense challenge for the future life in the city.

\footnotetext{
3 Rico A. et al., 2019. Carbon footprint of tourism in Barcelona, Tourism management, 70 (2019), 491-504

${ }^{4}$ https://ajuntament.barcelona.cat/dones/sites/default/files/documentacio/17_661_web_bcn_v2_0.pdf
} 
- Some residents are affected more than other; especially vulnerable groups are elderly, children, and pregnant woman. Similarly, heavily build-up areas are affected the most.

- An increased importance of friendly and climate-resilient open spaces is highlighted.

- Policy interventions are needed in order to preserve and foster the capacity of provisions originating from open spaces, as these are becoming critically scarce

Barcelona 2025; Global feedback processes have accelerated the global warming trend to an extent unpredicted by most climate scientists. Barcelona became a critically endangered region, exposing its population to risk and uncertainty. Rapidly changing climate manifests its power through a high variability and frequent occurrence of extreme events.

A number of torrid days (reaching over $33^{\circ} \mathrm{C}$ ) and the duration of droughts increased eight-fold. Intensive urbanization amplifies the urban heat island effect, making the build-up area hotter by $20^{\circ} \mathrm{C}$ comparing to the surrounding green areas 5 . The number of deaths counts for 2000 human lives per year due to the heat in Barcelona only ${ }^{6}$. Districts with the lowest coverage of green spaces are hit most heavily, as they become unbearably hot. These areas correspond with the poorer population, whereas elderly, children and pregnant women are the most vulnerable groups. Tropical nights exhausts people as they are not able to have a needed rest after a torrid day. Heat waves cause premature births, physical and mental diseases, but also financial shortages of poorer residents due to intense use of cooling technologies; also, resulting in higher energy use and thus intensifying the climate change.

At the same time, the city experiences severe rainfall shortages and thus water scarcity. Furthermore, fire hazards concern not only the Collserola, but appears in the neighbourhoods of Vallvidrera, Tibidabo i les Planes, Horta, Canyelles, or Torre Baró, where thousands of people reside.

By contrast, rainfall gains on intensity in form of a storm events which frequently flood the city; floods and landslides are threatening residents and causing ample economic damages. A $72 \%$ of impermeable surfaces ${ }^{7}$ and lack of climate-resilient green spaces in Barcelona are boosting impacts to maximum. Another critical water-related issue will soon emerge on the coastline, where the sea level may rise by additional $1 \mathrm{~m}$ and start to flood the recreational areas.

Citizens' health and wellbeing started to decrease. A discomfort from heat, droughts, fires, or storm events, has led to a higher demand for friendly and resilient open green spaces. Integrated policy action is required to preserve ecosystem provisions that are necessary for security and wellbeing of citizens.

\footnotetext{
${ }^{5,8}$ http://lameva.barcelona.cat/barcelona-pel-clima/en

${ }^{7}$ https://ajuntament.barcelona.cat/ecologiaurbana/en/what-we-do-and-why/energy-and-climate-change/climate-plan
} 